\title{
Internet Filtering in China in 2004-2005: A Country Study
}

\section{Citation}

OpenNet Initiative, Internet Filtering in China in 2004-2005: A Country Study (2005).

\section{Published Version}

http://opennet.net/sites/opennet.net/files/ONI_China_Country_Study.pdf

\section{Permanent link}

http://nrs.harvard.edu/urn-3:HUL.InstRepos:2794918

\section{Terms of Use}

This article was downloaded from Harvard University's DASH repository, and is made available under the terms and conditions applicable to Other Posted Material, as set forth at http:// nrs.harvard.edu/urn-3:HUL.InstRepos:dash.current.terms-of-use\#LAA

\section{Share Your Story}

The Harvard community has made this article openly available.

Please share how this access benefits you. Submit a story.

\section{Accessibility}


April 14, 2005

\section{Internet Filtering in China in 2004-2005: A Country Study}




\section{Internet Filtering in China in 2004-2005}

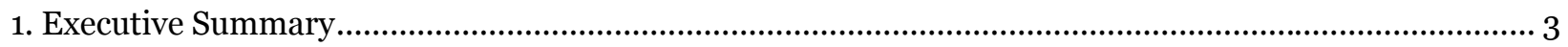

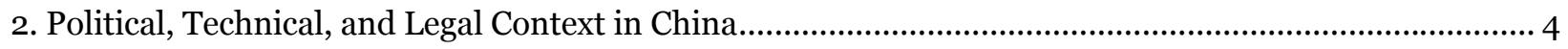

A. Sensitive / Controversial Topics for Media Coverage …..................................................................... 4

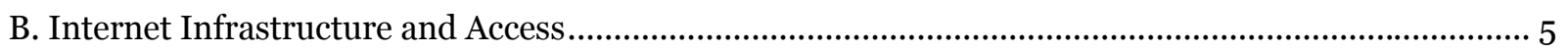

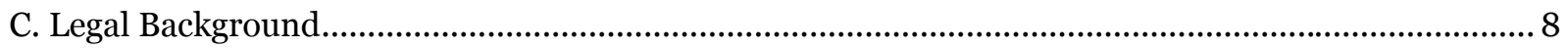

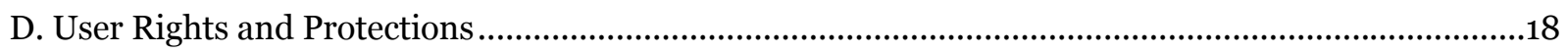

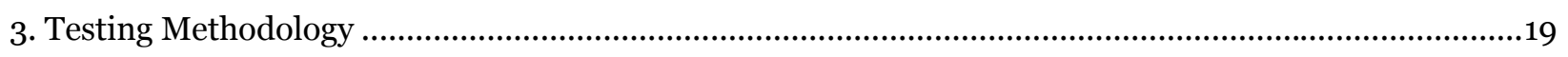

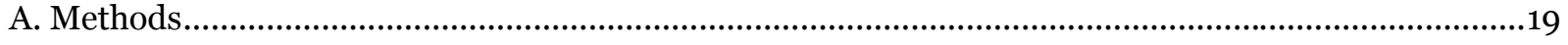

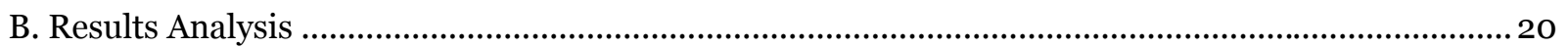

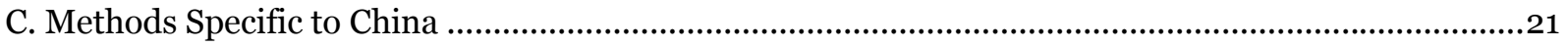

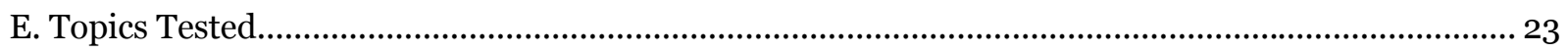

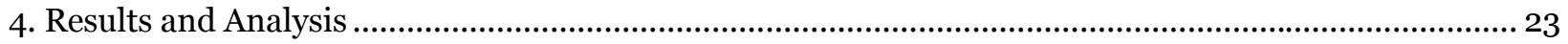

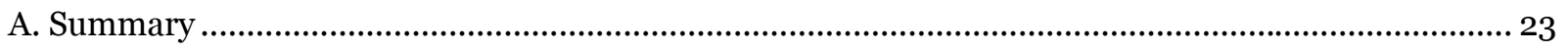

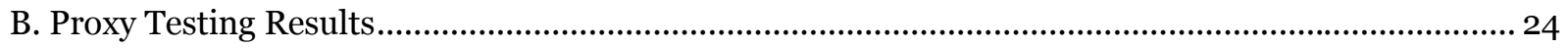

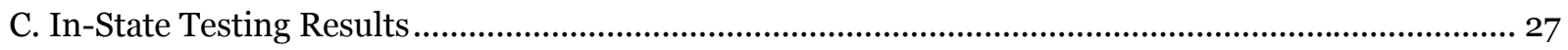

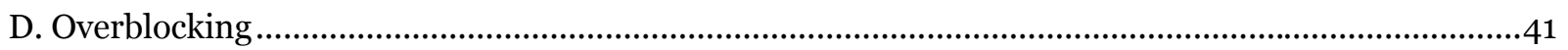

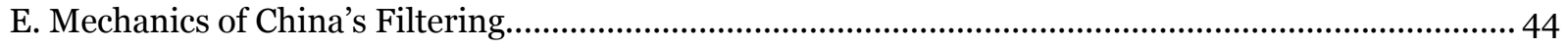

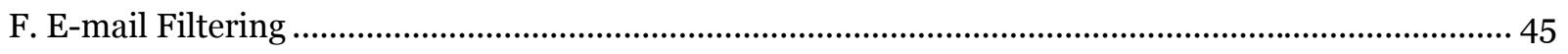

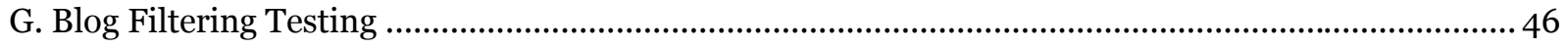

H. Google Cache Testing ............................................................................................................ 47

I. Filtering by Chinese Search Engines Baidu and Yisou......................................................................... 48

J. Restrictions on University On-Line Bulletin Board Systems .......................................................... 49

K. Restrictions on On-Line Discussion Forums ................................................................................ 50

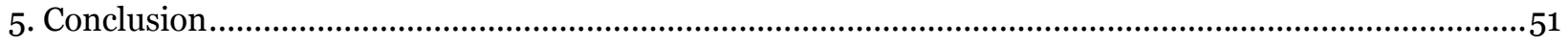

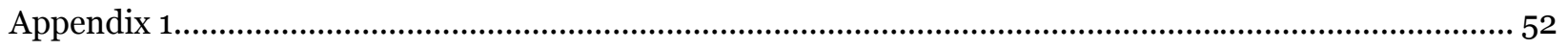

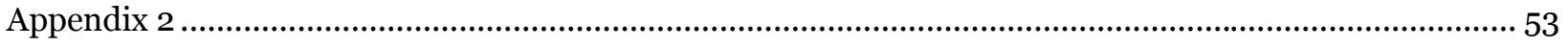

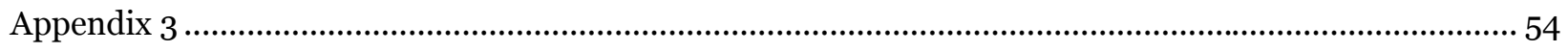

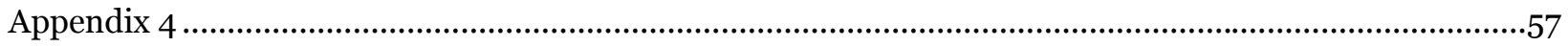




\section{EXECUTIVE SUMMARY ${ }^{1}$}

China's Internet filtering regime is the most sophisticated effort of its kind in the world. Compared to similar efforts in other states, China's filtering regime is pervasive, sophisticated, and effective. It comprises multiple levels of legal regulation and technical control. It involves numerous state agencies and thousands of public and private personnel. It censors content transmitted through multiple methods, including Web pages, Web logs, on-line discussion forums, university bulletin board systems, and e-mail messages. Our testing found efforts to prevent access to a wide range of sensitive materials, from pornography to religious material to political dissent. ONI sought to determine the degree to which China filters sites on topics that the Chinese government finds sensitive, and found that the state does so extensively. Chinese citizens seeking access to Web sites containing content related to Taiwanese and Tibetan independence, Falun Gong, the Dalai Lama, the Tiananmen Square incident, opposition political parties, or a variety of anti-Communist movements will frequently find themselves blocked. Despite conventional wisdom, though, ONI found that most major American media sites, such as CNN, MSNBC, and $\mathrm{ABC}$, are generally available in China (though the $\mathrm{BBC}$ remains blocked). Moreover, most sites we tested in our global list's human rights and anonymizer categories are accessible as well. While it is difficult to describe this widespread filtering with precision, our research documents a system that imposes strong controls on its citizens' ability to view and to publish Internet content.

Unlike the filtering systems in many other countries, China's filtering regime appears to be carried out at various control points and also to be dynamic, changing along a variety of axes over time. This combination of factors leads to a great deal of supposition as to how and why China filters the Internet. These complexities also make it very difficult to render a clear and accurate picture of Internet filtering in China at any given moment. Filtering takes place primarily at the backbone level of China's network, though individual Internet service providers also implement their own blocking. Our research confirmed claims that major Chinese search engines filter content by keyword and remove certain search results from their lists. Similarly, major Chinese Web log ("blog") service providers either prevent posts with certain keywords or edit the posts to remove them. We found also that some keyword searches were blocked by China's gateway filtering and not the search engines themselves. Cybercafés, which provide an important source of access to the Internet for many Chinese, are required by law to track Internet usage by customers and to keep correlated information on file for 60 days. As a further indication of the complexity of China's filtering regime, we found several instances where particular URLs were blocked

\footnotetext{
${ }^{1}$ The OpenNet Initiative is a collaborative partnership between three leading academic institutions: the Citizen Lab at the Munk Centre for International Studies, University of Toronto, Berkman Center for Internet \& Society at Harvard Law School, and the Advanced Network Research Group at the Cambridge Security Programme (Centre for International Studies) at the University of Cambridge. As with all OpenNet Initiative work, these reports represent a large team effort. The work of principal investigators Jonathan L. Zittrain and John G. Palfrey, Jr. on this research report was made possible by a grant from the John D. and Catherine T. MacArthur Foundation's Research and Writing Grants Program of the Program on Global Security and Sustainability. ONI thanks Che Dong, Alana Maurushat, Rebecca Vaughn, and a number of anonymous volunteers for contributing key research to this study.
} 
but the top-level domain of these URLs was accessible, despite the fact that the source of content appeared consistent across the domain - suggesting that filtering may be conducted at a finer level in China than in the other countries that we have studied closely. Moreover, China's Internet filtering appears to have grown more refined, sophisticated, and targeted during the years of ONI's testing.

China's intricate technical filtering regime is buttressed by an equally complex series of laws and regulations that control the access to and publication of material online. While no single statute specifically describes the manner in which the state will carry out its filtering regime, a broad range of laws - including media regulation, protections of "state secrets," controls on Internet service providers and Internet content providers, laws specific to cybercafés, and so forth - provide a patchwork series of rationales and, in sum, massive legal support for filtering by the state. The rights afforded to citizens as protection against filtering and surveillance, such as a limited privacy right in the Chinese Constitution, that otherwise might provide a counter-balance against state action on filtering and surveillance, are not clearly stated and are likely considered by the state to be inapplicable in this context.

China operates the most extensive, technologically sophisticated, and broad-reaching system of Internet filtering in the world. The implications of this distorted on-line information environment for China's users are profound, and disturbing.

\section{Political, Technical, AND Legal ConteXt in China}

\section{A. Sensitive / Controversial Topics for Media Coverage}

In China, a wide range of topics are considered sensitive or controversial by the government.

Media are heavily controlled and journalists are frequently punished for publishing information or stating positions that deviate from official Communist Party doctrine. ${ }^{2}$ Organized dissent and criticism of the Communist Party are not tolerated. 3 Coverage of any group that can organize large numbers of people is considered threatening. The Falun Gong spiritual movement, in particular, has been targeted for repression in recent years. 4

In general, China attempts to suppress publication of information related to "subversive" political movements and controversial state actions, including the Tiananmen Square uprising, 5 support for a free Tibet, ${ }^{6}$ the Falun Gong spiritual movement, ${ }^{7}$ criticism of China's human rights and social justice records, ${ }^{8}$

\footnotetext{
${ }^{2}$ He Qinglian, Media Control in China, Nov. 4, 2004, at http://www.hrichina.org/public/contents/8991.

${ }^{3}$ Qinglian, Media Control in China.

${ }^{4}$ Economist Intelligence Unit, Country Profile 2005: China at 18.

${ }^{5}$ Human Rights Watch, World Report 2005: China, January 2005, at http://hrw.org/english/docs/2005/01/13/china9809.htm.

${ }^{6}$ Jonathan Zittrain \& Benjamin Edelman, Internet Filtering in China, IEEE Internet Computing, March/April 2003, available at http://unpan1.un.org/intradoc/groups/ public/documents/APCITY/UNPAN011043.pdf.

${ }^{7}$ Zittrain \& Edelman, Internet Filtering in China.
} 
independent news media, ${ }^{9}$ and pro-democracy / pro-Western commentary. ${ }^{10}$ Calls for decreased censorship are often themselves censored. ${ }^{11}$ Journalists who report on unfavorable events or question the party line are often jailed on fabricated charges meant to discredit them. ${ }^{12}$ Additionally, the state actively suppresses "inappropriate" material including pornography, sex-related information, and obscenity. ${ }^{13}$ Methods of circumventing Internet filters and content restrictions are also censored. ${ }^{14}$

While China stopped subsidizing newspapers and magazines in 2003, the state still tightly controls the media sector. ${ }^{15}$ Foreign companies cannot invest in newspapers and must enter into partnerships or licensing agreements with Chinese firms to publish magazines. ${ }^{16}$ While the government generally controls what is published, it is stricter in some areas than others. ${ }^{17}$ Journalists and commentators often cannot know the boundaries for prohibited expression, and the risk of losing their jobs and facing civil or criminal liability leads to self-censorship. ${ }^{18}$

\section{B. Internet Infrastructure and Access}

According to the most recent study by the China Internet Network Information Center (CNNIC), China has 94 million Internet users, nearly half of whom have broadband access. ${ }^{19}$ Other studies estimate 130 million users by counting those who do not have a computer in their home but access the Internet from cybercafés. ${ }^{20}$ China has international bandwidth capacity measuring 74,429 megabits per second. Almost 60 million unique Internet protocol (IP) addresses have been assigned to computers in China. ${ }^{21}$

China's Internet regulatory policy authorizes four state organizations - now subsumed into the Ministry of Information Industry (MII) - to operate networks connected to the global Internet.22 The

\footnotetext{
${ }^{8}$ See, e.g., Reporters Sans Frontières, Reformist Journalists and Intellectuals Punished and Censored, Dec. 3, 2004, at http://www.rsf.org/article.php3?id_article=12008.

${ }^{9}$ Zittrain \& Edelman, Internet Filtering in China.

${ }^{10}$ China's influence extends even to broadcasters outside the state. See, e.g., Reporters Sans Frontières, Chineselanguage NTDTV harassed by Beijing, May 25, 2004, at http://www.rsf.org/article.php3?id_article=10439.

${ }^{11}$ See, e.g., Reporters Sans Frontières, Five Resign From Editorial Board in Solidarity With Dismissed Magazine Editor, Dec. 6, 2004, at http://www.rsf.org/article.php3?id_article=11726.

${ }^{12}$ Qinglian, Media Control in China, at 19.

${ }^{13}$ See, e.g. Nation's Fierce Smut Wars Wages Onward, China Daily, at http://news.xinhuanet.com/english/2005-01/22/content_2494594.htm.

${ }^{14}$ Censorware Project, SafeWeb Privacy Proxy Censored in China, Mar. 14, 2001, at http://censorware.net/article.pl?sid=01/03/14/0755209.

${ }^{15}$ Xinhua News Agency, Print Media Reform Involves 2000 Newspapers, 9000 Magazines, China Daily, Nov. 27, 2003, at http://www.chinadaily.com.cn/en/doc/2003-11/27/content_285360.htm.

${ }^{16}$ BusinessWeek Magazine, Foreign Magazines Facing China's Newsstand Fever, China Daily, Nov. 5, 2003, at http://www.chinadaily.com.cn/en/doc/2003-11/05/content_278774.htm.

${ }^{17}$ Economist Intelligence Unit, Country Profile 2005: China at 29

${ }^{18}$ Qinglian, Media Control in China.

${ }^{19}$ China Internet Network Information Center (CNNIC), $15^{\text {th }}$ Statistical Survey Report on the Internet Development in China, January 2005, at http://www.cnnic.net.cn/download/2005/2005012701.pdf.

${ }^{20}$ Net User Tally in China Nears $134 \mathrm{~m}$, South China Morning Post, Feb. 4, 2005, at http://www.asiamedia.ucla.edu/article.asp?parentid=20477.

${ }^{21} \mathrm{CNNIC}, 15^{\text {th }}$ Statistical Survey Report on the Internet Development in China.

${ }^{22}$ Asian Technology Information Program, Report ATIP98.090: The Internet In China, Nov. 3, 1998, at http://www.atip.org/public/atip.reports.98/atip98.090r.html.
} 
MII oversees China's Internet infrastructure; physical access is provided by nine state-licensed Internet access providers (IAPs), each of which has at least one connection to a foreign Internet backbone. ${ }^{23}$ IAPs peer at three Internet exchange points (IXPs) run by the state. ${ }^{24}$ IAPs grant regional Internet service providers (ISPs) access to backbone connections. Over 620 ISPs were registered in July 2001, and far more exist today. 25

Figure 1 - Internet Access Providers ${ }^{26}$

\begin{tabular}{|l|l|l|l|}
\hline Company Name & Audience & Network Name & $\begin{array}{l}\text { Bandwidth } \\
\text { (Mb/s) }\end{array}$ \\
\hline China Telecom & General public & CHINANET & 46268 \\
\hline China Netcom/CNCNet & $\begin{array}{l}\text { Broadband } \\
\text { users }\end{array}$ & CHINA169 & 19087 \\
\hline China Science and Technology Network & Researchers & CSTNET & 5275 \\
\hline China Unicom & Businesses & UNINET & 1645 \\
\hline China Mobile & & CMNET & 1130 \\
\hline China Education and Research Network & Schools & CERNET & 1022 \\
\hline China Intl. Economic and Trade Net & & CIETNET & $\mathbf{2}$ \\
\hline China Great Wall Communications & & CGWNET & $\begin{array}{l}\text { Under } \\
\text { construction }\end{array}$ \\
\hline China Satcom & & $\begin{array}{l}\text { Under } \\
\text { construction }\end{array}$ \\
\hline
\end{tabular}

The MII regulates ownership and operation of telecommunications services; the Ministry refused to allow foreign companies to offer Internet access in competition with China's ISPs until China was accepted for entry into the World Trade Organization in 2001. ${ }^{27}$

There has been considerable debate about the complicity of Western corporations in the development and maintenance of China's filtering system. China's Internet infrastructure includes equipment and software from U.S. companies, including Cisco Systems, Nortel Networks, Sun Microsystems, and 3COM. ${ }^{28}$ Cisco Systems in particular has been integral to China's Internet

${ }^{23}$ CNNIC, $15^{\text {th }}$ Statistical Survey Report on the Internet Development in China.

${ }^{24}$ CNNIC, $15^{\text {th }}$ Statistical Survey Report on the Internet Development in China.

${ }^{25}$ Human Rights Watch, Freedom of Expression and the Internet in China, at http://www.hrw.org/backgrounder/asia/china-bck-0701.htm.

${ }^{26}$ CNNIC, $15^{\text {th }}$ Statistical Survey Report on the Internet Development in China.

${ }^{27}$ Carolyn Duffy Marsan, China: ISPs Report Major Growth in 2004, Network World Fusion, Dec. 20, 2004, at http://www.nwfusion.com/newsletters/isp/2004/1220isp1.html.

${ }^{28}$ Asian Technology Information Program, Report ATIP98.090: The Internet in China See Greg Watson, China's Golden Shield: Corporations and the Development of Surveillance Technology in the People's Republic of China, at http://go.openflows.org/ (2001) (describing how American and European technology was used to build China's digital surveillance network); see also Ethan Gutmann, Losing the New China at 127-172 (2004). 
development. The core of China's Internet relies on Cisco technology; Cisco specifically implemented the backbone networks for ChinaNet ${ }^{29}$ and CERNet ${ }^{30}$, China's nation-wide educational network. Cisco's involvement continues to this day with the company's role in the development of China's "NextGeneration Network," known as CN2.31

Activists and human rights organizations have for years charged Cisco and other Western corporations with actively assisting China in developing censorship and surveillance systems. ${ }^{2}$ For example, Amnesty International, Human Rights Watch, and Reporters Sans Frontières have consistently highlighted the issues of corporate responsibility and Internet freedom raised by China's use of Western technologies. These groups allege that Western corporations have facilitated the construction of China's censorship and surveillance infrastructure, and that they may even be involved in the system's ongoing maintenance and operations.33

Companies such as Microsoft and Cisco respond to these charges by suggesting that they simply sell the technology to China; thus, they cannot and should not control how their customers use what they have bought. 34 However, at least one whistleblower has stated that Cisco specifically designed and developed a special router/firewall box for China. 35

In addition, the technologies that Cisco sold to China for backbone routing purposes -- Cisco 12000 series routers -- have packet filtering capability, allowing the routers to filter bi-directionally at the packet level and to implement up to 750,00o different filtering rules. ${ }^{6}$ These systems are designed to combat various Internet attacks, including Denial of Service (DoS) attacks and the spread of worms and viruses. For example, to combat the Code Red worm, Cisco released instructions on how to configure their routers' Access Control Lists to block the spread of the worm. 37 These same techniques can be applied to block political content. The particular technique described in Cisco's Code Red document

\footnotetext{
${ }^{29}$ Cisco Systems, Cisco Systems to be Key Supplier for Building China's Nation-Wide IP Backbone, Oct. 14, 1998, available at http://newsroom.cisco.com/dlls/fspnisapid67e.html.

${ }^{30}$ Cisco Systems, CERNET Strengthens Cooperation with Cisco Systems with Major Upgrade of National Backbone Network, Sept. 2, 1998, at http://newsroom.cisco.com/dlls/fspnisapia57d.html.

${ }^{31}$ Cisco Systems, Cisco Selected to Build Backbone and Premium Business Network for China Telecom's IP Next Generation Network, Nov. 11, 2004, at http://newsroom.cisco.com/dlls/2004/prod_111104.html.

${ }^{32}$ Greg Walton, China's Golden Shield: Corporations and the Development of Surveillance Technology in the People's Republic of China, available at http://www.ichrdd.ca/english/commdoc/publications/globalization/goldenShieldEng.html.

${ }^{33}$ See, e.g., Amnesty International, People's Republic of China: Controls tighten as Internet activism grows, Jan. 28, 2004, at http://web.amnesty.org/library/Index/ENGASA170012004; Human Rights Watch, China Tightens Internet Controls, Aug. 1, 2001, at http://www.hrw.org/press/2001/08/china-0801.htm; Reporters Sans Frontières, Internet Under Surveillance: China, June 22, 2004, at http://www.rsf.org/print.php3?id_article=10749; Rights \& Democracy (International Centre for Human Rights and Democratic Development), Human Rights at Risk on the Cyberbattlefield: The Sale of Security \& Surveillance Technology to China, at http://www.ddrd.ca//english/commdoc/publications/globalization/surveillancetechChina/briefingpaper.htm.

${ }^{34}$ Laura Rohde, Companies defend against Chinese censorship charge, IDG News Service, Dec. 2, 2002, at http://www.nwfusion.com/news/2002/1202china.html.

${ }^{35}$ Ethan Gutmann, Who Lost China's Internet?, The Weekly Standard, Feb. 15, 2002, available at http://www.weeklystandard.com/Utilities/printer_preview.asp?idArticle=922.

${ }^{36}$ Cisco Systems, Using Cisco 12000 Series IP Services Engine (ISE) Architecture to Enable the High-Speed Provider Edge, Oct. 1, 2001, at http://www.cisco.com/warp/public/cc/pd/rt/12000/prodlit/werr_wp.htm.

${ }^{37}$ Cisco Systems, Using Network-Based Application Recognition and ACLs for Blocking the "Code Red" Worm, at http://www.cisco.com/warp/public/63/nbar_acl_codered.shtml (last updated Apr. 6, 2005
} 
focuses on blocking incoming and outgoing access to URLs that contain certain keywords in the path. However, one of the rules employed to block the Code Red worm, Match protocol http url "*root.exe*", could just as easily be Match protocol http url "*falun*". 38

It is unlikely that Cisco would choose not to provide customer support or training for specific functionality of their products. Yet without official denial or confirmation, observers are left to speculate about their direct involvement in China's filtering regime.

\section{Legal Background}

China's legal regulation of the Internet is extraordinarily complex. The legal regime comprises requirements and prohibitions issued by multiple bodies and administrative agencies; our research indicates that at least a dozen entities have authority over Internet access and content in some form. 39 These rules frequently overlap and restate prior provisions. Conforming to these requirements is made more difficult by the broad, sweeping definitions that many regulations employ. Overall, China's legal controls over the Internet have expanded greatly since 2000, indicating increased attention to this medium of communication. Moreover, the number of regulatory bodies with a role in Internet control has increased. This may indicate intra-governmental competition for a voice in shaping a medium viewed as vital to China's economic growth and political stability.

\section{General Media Regulation}

A number of regulatory agencies combine to control tightly China's print and broadcast media. The General Administration of Press and Publication (GAPP) licenses and closely monitors publications, including newspapers, periodicals, books, and Web sites.40 GAPP is assisted by the General Administration for Customs, which confiscates publications deemed "harmful to the government." 41 China's State Administration of Radio, Film, and Television regulates radio, television, satellite, and Internet broadcasts ${ }^{42}$, in conjunction with the Ministry of Information Industry, which retains responsibility for control of the telecommunications and software industries and Internet content provider licensing. The Ministry of Public Security is responsible for general regulation of Internet

\footnotetext{
${ }^{38}$ Cisco Systems, Using Network-Based Application Recognition and Access Control Lists for Blocking the "Code Red" Worm, available at http://www.ccert.edu.cn/upload/1/35.pdf.

${ }^{39}$ See Appendix 2 for a list of these bodies.

${ }^{40}$ Congressional - Executive Commission on China, Freedom of Expression - Laws and Regulations, at http://www.cecc.gov/pages/virtualAcad/exp/explaws.php\#clampdown (translating "Notice Regarding Resolutely Clamping Down on Illegal Publishing Activities" of Jan. 25, 1996).

${ }^{41}$ Regulations on Customs' Administration of Printed Materials and Audio/Visual Materials Imported or Exported by Individuals Via Carriage or Post, July 10, 1991, translation available at http://www.cecc.gov/pages/virtualAcad/exp/explaws.php.

${ }^{42}$ See, e.g., Measures on the Administration of Foreign Satellite Television Channel Reception, Aug. 1, 2004; Measures on the Administration of Broadcasting Audio/Visual Programs over the Internet or Other Information Networks, Jan. 7, 2003, translations available at http://www.cecc.gov/pages/virtualAcad/exp/explaws.php; see generally Richard Cullen \& Pinky D. W. Choy, The Internet in China, 13 Colum. J. Asian L. 99, 116 (1999).
} 
access. 43 The State Secrecy Bureau classifies state secrets, which all citizens are required to "safeguard." 44 Finally, the Central Propaganda Department ensures that Chinese publishers print only material consistent with the Communist Party's ideology; the Department uses directives, screenings, and training sessions for publishers and their employees to accomplish this goal.45

\section{Internet Access Regulation}

China implements access controls for ISPs, ICPs, Internet subscribers, and cybercafé users.

Access control has always been part of China's Internet filtering system: in February 1994, one year before the Internet became commercially available to Chinese users, the State Council gave the Minister of Public Security overall responsibility for supervision of the Internet. 46

Regulation of Internet access has grown more comprehensive, specific, and extensive recently. On March 2, 2000 the State Council promulgated "Interim Procedures on Registration and Filing of Online Business Operations" 47 which, for the first time, explicitly recognized on-line businesses and required them to register and submit information on their personnel for "information checks." 48 In September 2000, the "Interim Measures on the Administration of Record and Registration of Profitmaking Websites" formalized registration procedures, instituted annual inspections of on-line businesses, and required all such businesses to list their registration number prominently on their Web sites. In addition, the State Council issued Order No. 292, “Measures on Internet Information Services," on September 25, 2000.49 This order reiterated and strengthened provisions contained in previous legislation, while establishing increased levels of control and enforcement. Specifically, Order 292 attempted to differentiate Web sites that provide information "involving the journalism, publication, education, medical care, medicines, and medical equipment and so on" -- both for-profit and non-profit -from other Internet businesses. $5^{\circ}$

\section{a. ISPs}

ISPs that want to provide service in China must obtain an operating license from MII. ${ }^{51}$ Access providers must record a customer's account number, phone number, and IP address, and Internet content

\footnotetext{
${ }^{43}$ See Human Rights Watch, Freedom of Expression and the Internet in China, at http://www.hrw.org/backgrounder/asia/china-bck-0701.htm; see also Congressional - Executive Commission on China, China's Censors, at http://www.cecc.gov/pages/virtualAcad/exp/expcensors.php.

${ }^{44}$ State Security Law, Feb. 22, 1993, translation available at http://www.cecc.gov/pages/virtualAcad/exp/explaws.php; see Congressional - Executive Commission on China, China's Censors.

${ }^{45}$ Congressional - Executive Commission on China, China's Censors.

${ }^{46}$ Regulations for the Safety Protection of Computer Information Systems, State Council Order No. 147.

${ }^{47}$ Interim Procedures on Registration and Filing of Online Business Operations, State Council, Mar. 2, 2000.

${ }^{48}$ Interim Procedures on Registration and Filing of Online Business Operations, Article 6; see Clara Liang, Red Light, Green Light: Has China Achieved Its Goals Through the 2002 Internet Regulations?, 35 Vand. J. Transnat'I L. 1417, 1433 (2001).

${ }^{49}$ Measures on Internet Information Services, State Council Order No. 292, Sept. 25, 2000, translation from iSinoLaw.com.

${ }^{50}$ Measures on Internet Information Services, Article 5.

${ }^{51}$ China Online, Ministry Profile: Ministry of Information Industry (MII), archived at http://web.archive.org/web/20031211153108/http://www.chinaonline.com/refer/ministry_profiles/MIIL3.asp.
} 
providers that publish, operate bulletin boards, or engage in journalism must keep copies of all content made available.52 ISPs are legally responsible for content they display.53 ISPs that fail to follow the law face revocation of their business license and arrest of company staff. 54

\section{b. ICPs}

Internet content providers must control both access to and use of on-line bulletin board services. State Council Order No. 292 required for-profit Internet content providers (ICPs) to apply for a special business license 55 and non-profit ICPs to file official records ${ }^{56}$. In addition, any ICP seeking to operate a bulletin board system (BBS) would also need to apply for a special license.57 The "Provisions on the Administration of Internet Electronic Messaging Services," promulgated on October 27, 2000, by the State Council, built upon the licensing requirements established by Order No. 292.58 ICPs seeking to operate bulletin boards or other electronic communication services were required to obtain approval from the Ministry of Information Industry (MII).59 To offer these services, ICPs had to create a comprehensive set of rules governing subscriber use of the service, consistent with applicable laws. ${ }^{60}$ The ICP must publish these rules prominently on its Web site. ${ }^{61}$ Additionally, the Provisions mandated that ICPs set up a secure registration and login system to allow the service to identify and track subscribers. ${ }^{62}$ ICPs were required to track subscribers' usage for 60 days, and to turn over such information to government agencies on request.63 Finally, ICPs were charged with monitoring all content on their services and immediately removing and reporting any inappropriate or illegal postings. ${ }^{64}$

\section{c. Subscribers}

A 1996 decree requires all subscribers to register with their local police bureau within the first 30 days of signing up with an ISP. 65 The same decree set up police computer investigation organizations to

\footnotetext{
52 Measures for the Administration of Internet Information Services, Sept. 25, 2000, translation available at http://www.cecc.gov/pages/virtualAcad/exp/explaws.php.

${ }^{53}$ Human Rights Watch, Freedom of Expression and the Internet in China (citing Measures For Managing the Internet Information Services).

${ }^{54}$ International Centre for Human Rights and Democratic Development, Review of China's Internet Regulations and Domestic Legislation, available at http://www.ichrdd.ca/english/commdoc/publications/globalization/legislationlnternetChinaEng.pdf.

${ }^{55}$ Measures on Internet Information Services, Article 7.

${ }^{56}$ Measures on Internet Information Services, Article 8.

${ }^{57}$ Measures on Internet Information Services, Article 9.

58 Provisions on the Administration of Internet Electronic Messaging Services, State Council, Oct. 27, 2000, translation from China Law \& Practice.

${ }^{59}$ Provisions on the Administration of Internet Electronic Messaging Services, Article 5.

${ }^{60}$ Provisions on the Administration of Internet Electronic Messaging Services, Article 6.

${ }^{61}$ Provisions on the Administration of Internet Electronic Messaging Services, Article 10.

62 Provisions on the Administration of Internet Electronic Messaging Services, Article 6.

${ }^{63}$ Provisions on the Administration of Internet Electronic Messaging Services, Article 14.

${ }^{64}$ Provisions on the Administration of Internet Electronic Messaging Services, Article 13.

${ }^{65}$ Regulations on the Administration of Internet Access Service Business Establishments [Internet Cafés], Sept. 29, 2002, translation available at http://www.cecc.gov/pages/virtualAcad/exp/explaws.php; see Human Rights Watch, Freedom of Expression and the Internet in China; Hermida, Behind China's Internet Red Firewall.
} 
investigate alleged violations. ${ }^{66}$ Beginning in 2000, China required ISPs to track their users' account numbers, when users are online, and the sites customers visit.67 ISPs must maintain detailed logs on subscribers' Internet usage for 60 days, and can be held responsible if their customers use the ISP's systems to violate laws. ${ }^{68}$ Because of these laws, ISPs often implement their own monitoring and censoring functions, further limiting subscribers' access to information. ${ }^{69}$

\section{d. Cybercafés}

While many Chinese citizens, especially in major cities, have home broadband or dial-up Internet connections, a substantial number of users continue to visit cybercafés - only some of which are licensed - that have become plentiful in recent years. ${ }^{70}$ China periodically increases its supervision of Internet cafés, which are known as "Net bars" or "wangba." 71 In 2001, the State Council conducted a three-month investigation into public Internet providers, closing over 8,00o Internet cafés. ${ }^{22}$ Police installed filtering software to block pornography and other "harmful" information at roughly 5,00o cafés in Liaoning province alone.73 Government regulation and surveillance of cybercafés increased dramatically following a fire in a Beijing cybercafé in 2002; subsequently, the state shut down 150,00o unlicensed cybercafés.74 China continues to scrutinize and shut down cybercafés. Between October and December 2004, China closed over 12,000 Internet cafés in a wave of increased enforcement, targeting in particular those located near primary and middle schools. 75 Children under age 16 are banned from cybercafés, 76 where customers often play violent video games. 77

All cafés are required to install software that blocks Web sites purportedly containing pornographic or "subversive" content. ${ }^{8}$ Cafés must keep detailed logs linking users to the pages they visited and recording access to any blocked pages; these records are reported to the Public Security

\footnotetext{
${ }^{66}$ Human Rights Watch, Freedom of Expression and the Internet in China.

${ }^{67}$ State Council, Administration of Internet Information Service Procedures, September 2000; Human Rights Watch, Freedom of Expression and the Internet in China.

${ }^{68}$ Human Rights Watch, Freedom of Expression and the Internet in China.

${ }^{69}$ Human Rights Watch, Freedom of Expression and the Internet in China.

70 In November 2004, China reported inspecting 1.8 million cybercafés. Xinhua News Agency, China Closes 1,600 Internet Cafés in Six Months, Xinhua Economic News Service, Nov. 1, 2004.

71 See "Wangba" Crusade, Red Herring.

72 Human Rights Watch, Freedom of Expression and the Internet in China.

${ }^{73}$ Human Rights Watch, Freedom of Expression and the Internet in China.

${ }^{74}$ Alfred Hermida, Behind China's Internet Red Firewall, BBC News Online, Sept. 3, 2002, at http://news.bbc.co.uk/1/hi/technology/2234154.stm.

${ }^{75}$ Associated Press, China Shuts Internet Cafés, The Guardian, Feb. 15, 2005, at http://www.guardian.co.uk/china/story/0,7369,1414734,00.html.

${ }^{76}$ China Gets Tough on Cyber Cafés, BBC News World Edition, Dec. 27, 2002, at http://news.bbc.co.uk/2/hi/asia-pacific/2608305.stm.

77 “Wangba” Crusade, Red Herring, Feb. 17, 2005, at http://www.redherring.com/Article.aspx?a=11300.

${ }^{78}$ Hermida, Behind China's Internet Red Firewall.
} 
Bureau. 79 Cafés must obtain and record users' identities by asking for their identification cards, and must keep these records for at least 60 days. ${ }^{80}$

We translated a copy of China's Internet café regulations to analyze the state's control over this form of access. ${ }^{81}$ The goals of the regulations are to provide good service to users and to promote socialism. ${ }^{82}$ Cafés must follow all applicable laws and must "self police." ${ }^{3}$ Regulatory responsibility for cafés is divided among several entities. The cultural departments at the county level and above must "examine and endorse" new cafés, and must control existing ones. ${ }^{84}$ The Public Security Bureau has responsibility for the "safety of information." ${ }_{5}$ The Department of Commerce registers cafés, issues permits, and inspects locations to ensure proper licensing. ${ }^{86}$ The Department of Telecommunications also has a role in café oversight. 87 Employees of these regulating agencies may not be involved in operating a café. 88

Cafés must obtain permission before commencing service. ${ }^{89}$ Companies that offer this type of service must have adequate capital, fire prevention systems, methods for controlling access to information, and appropriate technical and security personnel. ${ }^{\circ 0}$ Cafés cannot be located within 200 meters of an elementary school, middle school, or residential building. ${ }^{91}$ The process of obtaining approval is complex: cafés must submit information to the Culture Department of the government at the county level or above, followed by applying for an "information safety permit" and "fire safety permit" from the Public Security Bureau, then application for an "Internet culture business permit document" is made to the Culture Department, and finally the applicant applies to the Commerce Department for a business registration. ${ }^{22}$ Changing the café's location, size, interior, or number of computers requires additional permissions. 93

Cafés can only operate during designated hours, and cannot admit minors. 94 Users must register with their identification cards, and cafés must record this information, along with the computer used and

\footnotetext{
${ }^{79}$ Human Rights Watch, Freedom of Expression and the Internet in China; "Wangba” Crusade, Red Herring.

${ }^{80}$ Regulations on the Administration of Internet Access Service Business Establishments [Internet Cafés].

81 The regulations are available at http://www.zetronic.com.cn/news_details.asp?newsid=10015. We thank Stian Haklev for translation assistance.

${ }^{82}$ Chapter 1, 互联网上网服务营业场所管理条例》 ( 全文) (Internet Service Providers [Internet cafés] Operating Regulations).

${ }^{83}$ Chapter 1, Internet Service Providers [Internet cafés] Operating Regulations.

${ }^{84}$ Chapter 1, Internet Service Providers [Internet cafés] Operating Regulations.

${ }^{85}$ Chapter 1, Internet Service Providers [Internet cafés] Operating Regulations.

${ }^{86}$ Chapter 1, Internet Service Providers [Internet cafés] Operating Regulations.

${ }^{87}$ Chapter 1, Internet Service Providers [Internet cafés] Operating Regulations.

${ }^{88}$ Chapter 1, Internet Service Providers [Internet cafés] Operating Regulations.

${ }^{89}$ Chapter 2, Internet Service Providers [Internet cafés] Operating Regulations.

${ }^{90}$ Chapter 2, Internet Service Providers [Internet cafés] Operating Regulations.

${ }^{91}$ Chapter 2, Internet Service Providers [Internet cafés] Operating Regulations.

${ }^{92}$ Chapter 2, Internet Service Providers [Internet cafés] Operating Regulations.

${ }^{93}$ Chapter 2, Internet Service Providers [Internet cafés] Operating Regulations.

${ }^{94}$ Chapter 3, Internet Service Providers [Internet cafés] Operating Regulations.
} 
the time of use, maintaining it for 60 days and making it available to the Public Security Bureau and the Culture Department.95 Penalties for violations include fines and potential criminal liability. ${ }^{96}$

\section{Internet Content Regulation}

China maintains extremely strong controls over the material that users are allowed to post and to access on the Internet. These include long, complex, and expensive licensing requirements; mandatory registration and inspections; prescribed minimums for available capital and the number of employees; and broad restrictions on permissible types of content.

\section{a. Regulation of Internet Users}

China took initial steps to control how its citizens used the Internet in December 1997 when the Ministry of Public Security, pursuant to its authority under State Council Order No. 147, issued comprehensive regulations governing Internet use. The Ministry stated its goal was "to strengthen the security and the protection of computer information networks and of the Internet, and to preserve the social order and social stability". ${ }^{97}$ The regulations have three key sections, Articles 4 through 6.

Article 4 of the regulations proscribes individuals from using the Internet to harm national security; disclose state secrets; harm the interests of the State, of society, or of a group; or to take part in criminal activities. 98

Article 5 bars using the Internet to create, replicate, retrieve, or transmit information that incites resistance to the Constitution, laws, or administrative regulations; incites overthrow of the government or socialist system; incites division of the country or harms national unification; incites hatred or discrimination among nationalities or harms their unity; distorts the truth, spreads rumors, or destroys social order; promotes feudal superstitions, sexually suggestive material, gambling, violence, or murder; furthers terrorism, incites others to criminal activity, or openly insults or slanders other people; injures the reputation of state entities; or promotes other activities that violate the Constitution, laws, or administrative regulations. 99

Article 6 bars users from engaging in activities that could harm the security of computer information networks. It specifically forbids using networks or network resources without prior approval; changing network functions or adding / deleting information; adding to, deleting from, or altering materials stored, processed, or transmitted through the network; deliberately creating or transmitting viruses; or otherwise harming the network. ${ }^{100}$

Article 20 provides penalties for violations. It dictates that violators of Articles 5 or 6 will receive a warning, have any illegally earned income confiscated, be assessed a fine equal to or less than 5,000

\footnotetext{
${ }^{95}$ Chapter 3, Internet Service Providers [Internet cafés] Operating Regulations.

${ }^{96}$ Chapter 4, Internet Service Providers [Internet cafés] Operating Regulations.

97 Computer Information Network and Internet Security, Protection and Management Regulations, Article 1.

${ }^{98}$ Computer Information Network and Internet Security, Protection and Management Regulations, Article 4.

${ }^{99}$ Computer Information Network and Internet Security, Protection and Management Regulations, Article 5.

${ }^{100}$ Computer Information Network and Internet Security, Protection and Management Regulations, Article 6.
} 
renminbi (RMB) (approximately \$60o U.S.), and, for serious offenses, have their network access terminated for up to six months.101

The State Council supplemented these Regulations with telecommunications regulations issued in $2000 . .^{102}$

\section{b. Regulation of Content Providers}

State Council Order No. 292, promulgated in September 2000, established the first formal content restrictions for ICPs. Article 12 dictated that content providers were responsible for ensuring the legality of any information disseminated through their services and required ICPs to track and maintain records of user activity for 60 days. ${ }^{103}$ Article 15 specified nine restricted, relatively vague categories of information that cannot be produced, copied, published, or disseminated, comprising data

1. Which are against the principles prescribed in the Constitution;

2. Which endanger the security of the State, divulge the secrets of the State, overthrow the government, or damage the unification of the State;

3. Which harm the dignity and interests of the State;

4. Which instigate hatred, discrimination among the ethnic groups, or destroy the unity of nationalities;

5. Which break the religious policy of the State, spread evil cults or feudal superstition;

6. Which spread rumors, disturb the social order, and damage the social stability;

7. Which spread pornography, sex, gambling, violence, murder, terrorism or abetment;

8. Which insult or slander others and thus infringe upon others' lawful rights and interests; or

9. Which involve other contents prohibited by the laws and administrative rules. ${ }^{104}$

ICPs finding content on their services that violated one of the nine provisions were required to make a complete report to the relevant authorities ${ }^{105}$.

Two years later, on June 27, 2002, the General Administration of Press and Publishing (GAPP) teamed with the Ministry of Information Industry to release the "Interim Provisions on the Administration of Internet Publication." These provisions responded to mandates issued to these organizations in the State Council's "Administration of Publishing Regulations" and the "Measures on Internet Information Services.” The new provisions sought to reconcile controls over on-line publishing with those for print publications, and to unify Internet regulation and supervision efforts across agencies.

\footnotetext{
${ }^{101}$ Computer Information Network and Internet Security, Protection and Management Regulations, Article 20.

102 The Telecommunications Regulations ban individuals from using telecommunications networks to make, duplicate, issue, or disseminate the following information: (1) opposing constitutional principles; (2) jeopardizing national security, revealing state secrets, subverting state power, or undermining national security; (3) harming the property and interests of the states; (4) arousing ethnic animosities, ethnic discrimination, or undermining ethnic solidarity; (5) undermining state religious policies or promoting cults and feudal superstitions; (6) spreading rumors, disturbing social order, or undermining social stability; (7) spreading obscenity, pornography, gambling, violence, murder, terror, or instigating crime; (8) insulting or slandering others, or violating their legal rights and interests; (9) having other content prohibited by laws or administrative regulations. Telecommunications Regulations, State Council Order No. 291, issued Oct. 11, 2000.

${ }^{103}$ Measures on Internet Information Services, Article 12 (translation obtained from iSinoLaw.com).

${ }^{104}$ Measures on Internet Information Services, Article 15.

${ }^{105}$ Measures on Internet Information Services, Article 16.
} 
The provisions define "Internet publishing" as "an act of online dissemination whereby information service providers select, edit, and process works created by themselves or others and subsequently post the same on the internet or transmit the same to the end users via the internet for browsing, reading, use or downloading by the public." ${ }^{106}$ These "works" include formally published content that has appeared in books, newspapers, and periodicals as well as "edited and processed works of literature, art, natural science, social science and engineering technology." 107 This definition could apply to the material offered by every ICP, including non-business-oriented sites and personal Web sites, although the GAPP has not applied the provisions to personal sites. ${ }^{108}$

Along with restating previous regulations and adding more licensing and inspection requirements for ICPs, these provisions create an additional category of restricted information: content that "compromises public morality or refined indigenous culture and traditions."109 In addition to these completely proscribed categories, content involving state secrecy, social stability, or other "serious topics" must be reported to GAPP, and copies of such material submitted for official records. ${ }^{110}$ Finally, information "targeted at minors" was prohibited if it served to "induce[] minors to imitate acts that are contrary to public morality, illegal or criminal ${ }^{111}$," or if the material was "of horrific, cruel, or other such nature that is harmful to the physical and psychological health of minors." ${ }_{12}$

In addition to regulating content itself, the provisions required ICPs to implement procedural controls. Thus, ICPs had to create an "editor responsibility system" to review all content and editors were mandated to undertake "training, though the provisions do not define either of these requirements specifically. ${ }^{113}$

China has established rules for Internet broadcasting of audiovisual material as well, in an effort to harmonize on-line and off-line regulation of this content. In January 2003, the State Council passed "Measures on the Administration of Broadcasting Audio/Visual Programs over the Internet or Other Information Networks." The State Administration of Radio, Film, and Television was given jurisdiction over digital media content. The Measures require ICPs that broadcast news to obtain a license from the State Council Information Office, which required additional operating provisions.

The Ministry of Culture promulgated its "Interim Provisions on the Administration of Internet Culture," consisting mostly of restatements of existing rules and regulations, on May 10, 2003. The Ministry required all ICPs to register with its central or provincial office, in addition to the existing multiple registrations mandated by other regulations. ${ }^{114}$ The Provisions extended previously enacted

\footnotetext{
${ }^{106}$ Internet Publishing: China Pushes for Increased Supervision and Self-Discipline in the Industry, China Law and Practice, March 2005 (hereinafter "Internet Publishing").

107 Internet Publishing.

108 Internet Publishing.

109 Interim Provisions on the Administration of Internet Publication, Article 17 (translation obtained from iSinoLaw.com).

110 Interim Provisions on the Administration of Internet Publication, Article 16.

111 Interim Provisions on the Administration of Internet Publication, Article 18.

112 Interim Provisions on the Administration of Internet Publication, Article 17.

113 Interim Provisions on the Administration of Internet Publication, Article 21.

${ }^{114}$ Administration of Culture on the Internet Tentative Provisions (Summary), China Law \& Practice. Sept. 2, 2003.
} 
speech and content restrictions to cover information sent to cellular phones and other wireless devices, as well as to forms of content not specifically enumerated in previous legislation, such as video games. ${ }^{115}$

\section{c. State Secrets Controls}

The State Secrets Law is a critical and broadly defined part of China's Internet content control.

The State Secrets Law defines the term "state secrets" to include confidential information in areas ranging from social development, to technology, to international relations, to the national defense and economy. ${ }^{116}$ The law lists categories of restricted information, including "national defense," "secrets concerning important policy decisions on state affairs," "economic and social development," science and technology development, and criminal investigations. ${ }^{117}$ It also encompasses "secrets of political parties," restricting criticism and debate of public policy positions, and gives state agencies the authority to define additional categories. ${ }^{118}$ The State Secrets Bureau has wide discretion in determining what qualifies as a "state secret." 119 China has retroactively declared information a state secret. ${ }^{120}$ If convicted of providing state secrets to overseas individuals or organizations via the Internet, citizens face the death penalty. ${ }^{121}$

China's Constitution requires all citizens to "safeguard" state secrets. ${ }^{122}$ ICPs have additional responsibilities to "conscientiously perform secrecy protection duties and establish sound administration systems to strengthen supervision and monitoring." ${ }^{123}$ Violations of the State Secrets Law must be reported to authorities. ${ }^{124}$ Penalties for failure to comply with state secrets regulations are serious. The Supreme People's Court ruled that serious cases of state secrets violations can be punished with up to 10 years in prison, and violators may face the death penalty for cases of severe harm.125

\section{d. News}

News may be published online only by licensed print publishers. ${ }^{126}$ Non-licensed Web sites that wish to carry news may only publish information already publicly released by other news media. ${ }^{127}$ These

\footnotetext{
${ }^{115}$ Administration of Culture on the Internet Tentative Provisions (Summary), China Law \& Practice. Sept. 2, 2003.

${ }^{116}$ Law of the People's Republic of China on Guarding State Secrets, translation available at http://www.cecc.gov/pages/newLaws/protectSecretsENG.php.

${ }^{117}$ Amnesty International, State Secrets - A Pretext for Repression, May 1996, at http://web.amnesty.org/library/index/engasa170421996\#SSL.

${ }^{118}$ Amnesty International, State Secrets - A Pretext for Repression.

119 See Human Rights in China, Who's Who in Labor \& State Secrets, at http://www.hrichina.org/public/contents/article?revision\%5fid=18104\&item\%5fid=18103 (Oct. 25, 2004).

${ }^{120}$ International Centre for Human Rights and Democratic Development, Review of China's Internet Regulations and Domestic Legislation.

${ }^{121}$ Amnesty International, State Secrets - A Pretext for Repression.

122 Congressional-Executive Committee on China, Silencing Critics by Exploiting National Security and State Secrets Laws, at http://www.cecc.gov/pages/virtualAcad/exp/expsecurity.php.

123 Articles 8 \& 10, Provisions on the Administration of the Protection of Secrets on Internationally Networked Computer Information Systems, translated at http://www.cecc.gov/pages/virtualAcad/exp/expsecurity.php.

${ }^{124}$ Congressional-Executive Committee on China, Silencing Critics by Exploiting National Security and State Secrets Laws.

125 Supreme People's Court on Stealing State Secrets, Xinhua News Agency, Jan. 21, 2001.

${ }^{126}$ Interim Provisions on the Administration of Internet Websites Engaged in News Posting Operations, Nov. 1, 2000, translation available at http://www.cecc.gov/pages/virtualAcad/exp/explaws.php.
} 
sites must obtain approval from state information offices and from the State Council Information Agency. ${ }^{128}$ To be recognized as an online publisher, organizations must undertake the same licensing, and follow the same regulations, required for print publishing, an arduous task. ${ }^{129}$

Thus, China seeks to ensure that citizens can access only news from sources under state control. For example, during the Severe Acute Respiratory System (SARS) outbreak, official online sources and print newspapers disclosed only a few cases of "atypical pneumonia"; they stated that there was no epidemic, rumors to the contrary were false, and any illnesses could be attributed to "changes in the weather." ${ }^{30}$ Many citizens learned about SARS through informal channels of communication, such as simple messaging service (SMS) messages over cellular phones, rather than through official news sources. ${ }^{131}$

\section{e. Content Controls for Cybercafés}

Cybercafés operate under additional content regulations. The operators and patrons of these establishments may not access, create, download, or transmit information that is contrary to constitutional principles; that harms China's unity, sovereignty, or territorial integrity; that reveals national secrets, damages national security, or harms the state's reputation; that incites ethnic hatred or discrimination; that harms ethnic unity, customs, or traditions; that is contrary to national religious policy or that spreads superstition; that spreads rumors or disturbs public order; that spreads obscenity or violence; that teaches criminal behavior; that defames others or infringes their legal rights; that harms public morality; or that is otherwise unlawful.132

Furthermore, cybercafé users are prohibited from creating or spreading computer viruses, illegally accessing computer systems, or engaging in other unlawful activities. ${ }^{133}$ The cafés cannot offer access to gambling games or sites. ${ }^{134}$ Owners must install network monitoring equipment; if they detect that customers are accessing unlawful material, or engaging in forbidden activities, the café must disconnect the user and report them to the local Culture Department. ${ }^{135}$ Penalties for violations include fines and potential criminal liability. ${ }^{136}$

\footnotetext{
127 See China's Internet: An Uncertain Future, China Law \& Practice.

${ }^{128}$ Congressional-Executive Committee on China, International Agreements and Domestic Legislation Affecting Freedom of Expression, at http://www.cecc.gov/pages/virtualAcad/exp/explaws.php.

${ }^{129}$ To see how the process works, visit http://www.cecc.gov/pages/virtualAcad/exp/bookflow.php .

${ }^{130}$ Congressional-Executive Committee on China, Information Control and Self-Censorship in the PRC and the Spread of SARS, at http://www.cecc.gov/pages/news/prcControl_SARS.php.

${ }^{131}$ See, e.g., Irene Wang, Text Messages Boost SARS Fight, South China Morning Post, Nov. 4, 2003 , at 3.

132 Chapter 3, Internet Service Providers [Internet cafés] Operating Regulations.

${ }^{133}$ Chapter 3, Internet Service Providers [Internet cafés] Operating Regulations.

${ }^{134}$ Chapter 3, Internet Service Providers [Internet cafés] Operating Regulations.

${ }^{135}$ Chapter 3, Internet Service Providers [Internet cafés] Operating Regulations.

${ }^{136}$ Chapter 4, Internet Service Providers [Internet cafés] Operating Regulations.
} 


\section{f. Extra-legal Content Controls}

Content control in China occurs through informal as well as formal measures. Thus, the Internet Society of China pressures content and access providers to agree to a "Public Pledge of Self-Regulation and Professional Ethics." ${ }^{37}$ Companies often accede; Yahoo! agreed to the pledge in 2002, and filters content available to users at its Chinese language portal. ${ }^{138}$ Internet regulation in China is based on the philosophy that "one is responsible for what one publishes." ${ }^{39}$ Thus, Internet companies in China practice a high degree of self-censorship. These companies frequently prefer to focus on sports and entertainment rather than risk being shut down. ${ }^{140}$ ISPs perform self-censorship, including using employees who lead teams of volunteers to monitor and moderate chat rooms and bulletin boards.141 China can thus filter content through voluntary, informal measures, as well as via formal legal or technological means.

Users act as an additional regulatory mechanism. Some citizens view Internet regulation as necessary, and monitor Web sites, chat rooms, and bulletin boards for inappropriate content, reporting violations to the authorities. ${ }^{142}$

\section{User Rights and Protections}

China's laws and regulations do not generally provide comprehensive rights and protections to Internet users. There is often tension between formal legal rights and those recognized in actual cases. For example, consider a right to privacy. Article 38 of China's Constitution refers to a fundamental right of personal dignity, believed by most Chinese legal scholars to incorporate a right of privacy. ${ }^{143}$ Article 40 provides for the freedom and privacy of citizens' communications, and bars other organizations and individuals from infringing on those rights. The same Article, though, contains restrictions on or permits deprivation of a citizen's privacy or correspondence rights by public authorities to "meet the needs of state security" or "investigate criminal offenses" - broad, ambiguous exceptions. Some of China's legislation alludes to a similar right of privacy. However, Chinese constitutional jurisprudence does not recognize a fundamental right of privacy in action.

Legislation governing Internet users contains the same dichotomy. Certain regulations partially recognize a right to privacy. For example, Internet users' personal information is protected against

\footnotetext{
${ }^{137}$ See Internet Society of China, Public Pledge of Self-Regulation and Professional Ethics for China Internet Industry, available at http://www.isc.org.cn/20020417/ca102762.htm (July 19, 2002).

138 Sumner Lemon, Yahoo Criticized for Curtailing Freedom Online, PC World, Aug. 12, 2002, at http://www.pcworld.com/news/article/0,aid,103865,00.asp.

${ }^{139}$ Lokman Tsui, Internet in China: Big Mama is Watching You, July 2001, at http://www.lokman.nu/thesis/010717thesis.pdf.

140 Tsui, Internet in China: Big Mama is Watching You.

${ }^{141}$ International Centre for Human Rights and Democratic Development, Review of China's Internet Regulations and Domestic Legislation

${ }^{142}$ Bobson Wong, A Matter of Trust: The Internet and Social Change in China, China Rights Forum, Nov. 3, 2003, at http://www.hrichina.org/fs/downloadables/pdf/downloadable-resources/Bobson_Wong.pdf?revision_id=10352.

${ }^{143}$ China's Civil Law General Principles protect both personal dignity and the "right of reputation," and have been construed by the Supreme People's Court to include the right to privacy. Most likely, Chinese legal scholars extrapolate this conclusion from the relevant SPC decisions. See Privacy Protection in China's Cyberspace, China Law \& Practice, February 2003.
} 
unauthorized public disclosure by electronic messaging service providers. ${ }^{144}$ Users whose personal information is disclosed, in violation of this provision, can sue for damages and injunctive relief. ${ }^{145}$ Similarly, it is illegal to use computer information systems to steal or disrupt others' information or jeopardize the lawful interests of citizens; violators risk civil penalties. ${ }^{146}$

User communications also enjoy protection, at least in theory. Regulations affirm the freedom and privacy of users' e-mails and ban others from infringing upon their privacy. Violators who illegally intercept, modify, or delete others' e-mails face criminal liability. ${ }^{147}$ Even compulsory seizure of e-mails and other private telecommunications by the state is limited, according to the laws, to instances where the public security authority, public procurator authority, or the national security authority must do so to investigate a national security threat or criminal conduct. ${ }^{148}$ Such seizures are formally governed by specific criminal procedure requirements. ${ }^{149}$

However, the state possesses the power to regulate Internet content and to demand that ISPs and Internet Content Providers (ICPs) turn over personal information of Internet users who violate the laws or post prohibited content (a term defined broadly). Upon official request, an ISP or ICP must provide the user's name, IP address, e-mail address, user name, information on any changes in IP address and use, and all data saved by the service provider's computer when the prohibited content or illegal conduct took place, including time, content, originating source, and system logs. ${ }^{150}$

Thus, while China ostensibly provides some protection to users in the form of legally guaranteed rights, these safeguards rarely function in practice.

\section{TESTING METHODOLOGY}

\section{A. Methods}

ONI performs technical testing across multiple levels of access at multiple time intervals in a number of regions around the world. The team analyzes results within the contextual framework of the target state's filtering technology, law, and regulations. To obtain meaningful, accurate results we seek to:

- generate lists of domain names and URLs that have been or are likely to be blocked, based upon background research into relevant social and political issues in China;

- enumerate ISPs and national routing topography;

\footnotetext{
${ }^{144}$ Article 12, Administration of Internet Electronic Messaging Service Provisions.

145 Article 19, Administration of Internet Electronic Messaging Service Provisions.

${ }^{146}$ Article 25, Protection of the Safety of Computer Data Systems Regulations; Article 58(2), Telecommunications Regulations.

147 Article 4.2, Internet Security Decision.

${ }^{148}$ Article 66, Telecommunications Regulations.

149 Article 116, Criminal Procedure Law.

150 Ministry of Public Security, Questions Relevant to the Implementation of the Circular.
} 
- determine the type, location, and behavior of the filtering technology;

- deploy network interrogation and enumeration software at multiple access points; and

- conduct a thorough statistical analysis of results.

Determining which URLs to test is a vital component of our research, as it reveals the filtering system's technical capacity and content areas subject to blocking. ONI employs three types of lists:

- a list of "high impact" sites reported to be blocked or likely to be blocked in the state due to their content (for example, political opposition);

- a "global list" containing a control list of manually categorized Web sites reflecting a range of Internet content (for example, news and hacking sites), intended in part to enable comparisons across multiple states; and

- a multilingual list of significant key words used to generate significantly larger lists through search engine queries.

To explore Internet filtering, we deploy network interrogation devices and applications, which perform the censorship enumeration, at various Internet access levels. These tools download the ONI testing lists and check whether specific URLs and domains are accessible from that point on the network. Interrogation devices are designed to run inside a state (i.e., behind its firewall) to perform specific, sensitive functions with varying degrees of stealth. Similarly, ONI distributes interrogation applications to trusted volunteers who run the software inside the state. For testing, depending upon a series of local factors, ONI obtains network access at multiple levels through a combination of:

- Proxy servers,

- Long distance dial-up,

- Distributed applications, and

- Dedicated servers.

During initial testing, we use remote computers located in states that filter. These remote computers are located behind the state's firewalls yet allow access to clients connecting from the wider Internet. We attempt to access the URL and domain name lists through these computers to reveal what content is filtered, and how consistently it is blocked. The ONI team also tests these lists from control locations in non-filtered countries. The testing system flags all URLs and domains that are accessible from the control location, but inaccessible from ones inside the target state, as potentially blocked.

\section{B. Results Analysis}

We carefully analyze the data obtained from testing to document the nature of filtered content, to explore the technical capabilities of the target state, and to determine areas that require in-depth study during testing from inside the state's firewall. In particular, ONI examines the response received over HTTP when attempting to access filtered content. In many countries, when content is filtered, users generally receive a "block page" - a Web page with text indicating that the requested content cannot be accessed. In China, however, filtering can be less obvious or transparent, appearing to be network errors, redirections, or lengthy timeouts rather than deliberate blocking. We analyze HTTP headers - text sent from the Web server to the browser - to derive information about both the server and the requested page. 
This information is generally hidden from the end user. However, these headers can indicate whether content was successfully accessed or was inaccessible. If an error occurs, the HTTP protocol returns codes that indicate the type of error in the header. Thus, by analyzing the headers captured during testing, we seek to distinguish between errors caused by Internet filtering and more mundane, unintentional network connection errors.

We classify results in one of four categories:

- URL was accessible both through the local connection and the remote computer (not filtered);

- URL was accessible through the local connection but inaccessible through the remote computer, which returned a different HTTP response code (possibly filtered);

- URL was accessible through the local connection but inaccessible through the remote computer due to a network connection error (possibly filtered, but not definitive); or

- URL was accessible through the local connection but inaccessible through the remote computer; the remote computer returned a block page (filtered).

If a URL is inaccessible through both the local connection and the remote computer, we consider it "dead" and remove it from the results. This result indicates that the URL's content was not available to Internet users generally at the time of our testing, making the URL irrelevant for our testing.

The ONI team analyzes blocked, unblocked, and uncertain URLs both at an aggregate level (to estimate the overall level of filtering) and at a category level (to indicate what types of content the state seeks to control). We publish state-specific studies, such as this one on China, that provide background on a state's political and legal system, lists of tested sites, and analysis of results to reveal and analyze, to the greatest extent we can given the data we are able to collect, what information a state blocks and how it does so. We note, however, that our results and analysis capture a "snapshot" of a state's filtering system for a specific point or period of time; governments can and do alter the content they block dynamically.

\section{Methods Specific to China}

We tested China's Internet filtering through four methods. First, we were able to deploy an internally developed application within China to test what content was, and was not, blocked by the state's system. Volunteers used this application, along with manual checking of Web sites, to probe China's filtering from a number of access points inside the country. Second, we accessed proxy servers in China to duplicate and augment this in-state testing. Third, we created content on Web logs ("blogs") on three of China's most popular blog providers to evaluate the services' keyword filtering mechanisms. Finally, we sent a series of test e-mail messages to, and from, accounts hosted by several Chinese ISPs.

China's sophisticated filtering system makes testing its blocking difficult. For most states in which we test, an attempt to access a filtered site returns a block page indicating the requested site is prohibited and, occasionally, offering general reasons for this ban and an opportunity to request reconsideration of the decision to block access to the given site. In China, however, a request for a filtered Web page returns a network timeout; testing from a remote location via a proxy server in China generally returns any one of a series of HTTP error codes. ${ }^{151}$ In some cases, this included an error indicating the

\footnotetext{
151 See generally R. Fielding et al., HTTP/1.1: Status Code Definitions, available at http://www.w3.org/Protocols/rfc2616/rfc2616-sec10.html (June 1999).
} 
requested page did not exist (known as a "404 error"), ${ }^{152}$ even though we could successfully, and simultaneously, access the page from outside China. Furthermore, our testing of "control" sites known to be accessible in China (for instance, Web sites of state agencies) through proxy servers returned errors for approximately $20 \%$ of our requests. In our proxy testing analysis, we evaluate any site that we could access from outside China, but not from inside China in the majority of our tests, as blocked. We also attempted to identify overblocking, where China's filtering prevented access to pages with unrelated content at domain names and URLs similar to those of sites identified by news reports and previous testing as containing sensitive content.

Moreover, China's filtering system presents a risk of "false positive" results during testing. When a user attempts to access a blocked site, the filtering system resets the user's connection to that site using a TCP RST packet; subsequently, the system advertises a TCP window size of zero for that Web server. The user is unable to connect to that server's IP address until the system advertises a window size greater than zero. Our in-state testing included an instance of this condition: a domain that had been accessible prior to the testing of a URL (www.poets4peace.com/peacehall.htm) containing a potentially targeted string was blocked after a request for a URL on that site with a prohibited keyword. Even though subsequent URL requests were for unrelated content, the disruption caused by the zero window size condition persisted and prevented the tester from reaching those pages.

We conducted testing in several stages, and analyze results by topic (below). The first component was similar to our "high impact" list tests in other states we examined, checking a collection of URLs with content on or domain names including sensitive topics (for example, a page with Falun Gong material, or a URL such as www.falungong.com). The second testing phase built on our past data on filtering in China by checking a set of domains known to be of concern. Additionally, we tested URLs containing words or strings of letters similar to those found in pages on blocked topics (for example, testing URLs containing the strings "falu" or "flg" to probe filtering of Falun Gong content), but that hosted pages with content unrelated to the sensitive subject. Finally, we tested a "long list" comprised of the top Google search results, in English and in Chinese, for keywords known to be sensitive and filtered. ${ }^{153}$

\section{Comparison of Testing Methods}

Due to the complications of testing filtering in China, we sought to combine both proxy testing and in-state testing for this report. We found a $78 \%$ correlation between the two methods, with almost all the sites we were able to access through the proxy also accessible in-state. However, only $60 \%$ of the sites identified as blocked during proxy testing were confirmed as such during the in-state portion. The discrepancies were concentrated in the sites tested to determine overblocking (filtering of URLs similar to those containing targeted content, but with unrelated subject matter): $82 \%$ of the blocks during proxy testing of sites sensitive content were confirmed during in-state testing and only $22 \%$ of the corresponding blocks of unrelated content were thus verified. Potential explanations include the difficulty

\footnotetext{
152 See 404 error, Wikipedia, at http://en.wikipedia.org/wiki/404_error.

${ }^{153} \mathrm{ONI}$ compiled these keywords from a list of terms blocked by the instant messaging software QQ. See The Words You Never See in Chinese Cyberspace, China Digital News, at

http://journalism.berkeley.edu/projects/chinadn/en/archives/002885.html\#more (Aug. 30, 2004).
} 
of separating technical difficulties from intentional action, the limited scope of both tests (five proxies, one in-state run), and the dynamic nature of filtering in China (filtering methods may have changed during our testing).

\section{Figure 2 - Testing Method Consistency}

\begin{tabular}{|l|c|c|c|}
\hline Overall & In-State Match & In-State Opposite & Consistency \\
\hline Blocked in Proxy Testing & 38 & 25 & $60 \%$ \\
\hline Accessible in Proxy Testing & 59 & 2 & $97 \%$ \\
\hline TOTALS & $\mathbf{9 7}$ & $\mathbf{2 7}$ & $\mathbf{7 8 \%}$ \\
\hline
\end{tabular}

\section{E. Topics Tested}

Because of the technical challenges of testing in China, including the TCP connection termination and "ZeroWindow" condition described below, we performed limited testing in the state. Our testing focused on subjects known to be sensitive to China. These include political subjects, such as Tibetan independence, Taiwanese independence, and the Tiananmen Square incident of June 4, 1989; religious subjects, such as the banned Falun Gong / Falun Dafa movement and the Dalai Lama; and broad subjects of concern, such as human rights in China, general political opposition, anti-Communist material, and general news.

\section{RESULTS AND ANALYSIS}

\section{A. Summary}

Our results demonstrate that China's blocking of sensitive content - such as that related to the banned Falun Gong spiritual movement, Tibetan independence, or Taiwan - is extensive. We documented instances of overblocking, where sites with superficial similarities to those with sensitive material, but different content, were filtered. This likely indicates China's willingness to tolerate blocking unrelated content to prevent access to sensitive materials. The state's filtering is not perfect - we were able to circumvent keyword detection for blog posts, and to obtain some filtered material at alternative locations - but it is nonetheless quite thorough. China's filtering regime is one of the most sophisticated in its ability to detect and prevent access to content that the state considers prohibited. 


\section{B. Proxy Testing Results}

\section{Falun Gong}

Every site we tested related to the Falun Gong movement was blocked in both of our tests.

\section{Figure 3 - Falun Gong Sites}

\begin{tabular}{|l|c|c|}
\hline Sites Tested & In-State Result & Proxy Result \\
\hline http://www.faluncanada.net/ & Blocked & Blocked \\
\hline http://www.falundafa.org/ & Blocked & Blocked \\
\hline http://www.faluninfo.net/ & Blocked & Blocked \\
\hline http://www.fofg.org/ & Blocked & Blocked \\
\hline http://www.faluninfo.net/ & Blocked & Blocked \\
\hline http://www.stanford.edu/group/falun/ & Blocked & Blocked \\
\hline http://www.let.leidenuniv.nl/bth/falun.htm & Blocked & Blocked \\
\hline Total (7 sites) & $\mathbf{1 0 0 \%}$ & $\mathbf{1 0 0 \%}$ \\
\hline
\end{tabular}

\section{News}

Our news testing focused on sites that China has blocked previously, including Epoch Times, Boxun (also known as Peacehall), the Voice of America service, and the BBC. Our results confirm that China filters these news sources, at a number of different URLs. The in-state and proxy tests returned different results with regards to the two sites hosted within China itself. Further research is necessary to determine the extent to which these sites make available content China otherwise attempts to filter.

\section{Figure 4 - News Sites}

\begin{tabular}{|l|c|c|}
\hline Sites Tested & In-State Result & Proxy Result \\
\hline http://www.boxun.com.cn/ & Accessible & Blocked \\
\hline http://www.voanews.95.cn/ & Accessible & Blocked \\
\hline http://www.epochtimes.com/ & Blocked & Blocked \\
\hline http://www.peacehall.com/ & Blocked & Blocked \\
\hline http://news.bbc.co.uk/ & Blocked & Blocked \\
\hline http://www.voa.gov/ & Blocked & Blocked \\
\hline http://www.voanews.com/ & Blocked & Blocked \\
\hline Total (7 sites) & $\mathbf{7 1 \%}$ & $\mathbf{1 0 0 \%}$ \\
\hline
\end{tabular}

\section{Political Topics}

In this category, we checked sites containing anti-Communist content, pages with material related to the Tiananmen Square incident, the site for the non-governmental organization Human Rights in 
China, and various pro-democracy Web sites. We found extensive blocking in all categories, including anti-Communist sites focused on China. However, we were able to access a CNN site on the Tiananmen Square incident and a site calling for the American boycott of Chinese-made goods. The majority of sites within this category were tested via proxy only; see above for a comparison of proxy and in-state results.

\section{Figure 5 - Political Sites}

\begin{tabular}{|c|c|c|c|}
\hline Sites Tested & $\begin{array}{c}\text { In-State } \\
\text { Result }\end{array}$ & $\begin{array}{l}\text { Proxy } \\
\text { Result }\end{array}$ & Category \\
\hline http://edition.cnn.com/SPECIALS/2001/tiananmen/ & Accessible & Accessible & Tiananmen \\
\hline http://www.hrichina.org/ & Blocked & Blocked & Human Rights \\
\hline http://www.tsquare.tv/ & Blocked & Blocked & Tiananmen \\
\hline http://www.fillthesquare.org/ & Blocked & Blocked & Tiananmen \\
\hline http://www.64memo.com/ & Blocked & $\mathrm{N} / \mathrm{A}$ & Tiananmen \\
\hline http://www.spacepub.com/users/china/ & $\mathrm{N} / \mathrm{A}$ & Accessible & Boycott \\
\hline $\begin{array}{l}\text { http://www.writing.upenn.edu/ afilreis/50s/ } \\
\text { theoharis.html }\end{array}$ & $\mathrm{N} / \mathrm{A}$ & Blocked & Anti-Communist \\
\hline http://www.schwarzreport.org/ & $\mathrm{N} / \mathrm{A}$ & Blocked & Anti-Communist \\
\hline http://www.niagara.com/ freedom/anticom/first.htm & $\mathrm{N} / \mathrm{A}$ & Blocked & Anti-Communist \\
\hline http://www.informationblast.com/Anti-communism.html & $\mathrm{N} / \mathrm{A}$ & Blocked & Anti-Communist \\
\hline http://www.fact-index.com/a/an/anti_communism.html & $\mathrm{N} / \mathrm{A}$ & Blocked & Anti-Communist \\
\hline $\begin{array}{l}\text { http://www.colorado.edu/AmStudies/lewis/2010/ } \\
\text { mccarthy.htm }\end{array}$ & $\mathrm{N} / \mathrm{A}$ & Blocked & Anti-Communist \\
\hline $\begin{array}{l}\text { http://groups.yahoo.com/group/ } \\
\text { americananticommunists/ }\end{array}$ & $\mathrm{N} / \mathrm{A}$ & Blocked & Anti-Communist \\
\hline http://en.wikipedia.org/wiki/Anti-communism & $\mathrm{N} / \mathrm{A}$ & Blocked & Anti-Communist \\
\hline http://newstrolls.com/news/dev/guest/010899-2.htm & $\mathrm{N} / \mathrm{A}$ & Blocked & Opposition \\
\hline http://www.svdc.org/Main.html & $\mathrm{N} / \mathrm{A}$ & Blocked & Pro-democracy \\
\hline http://www.innermongolia.org/ & $\mathrm{N} / \mathrm{A}$ & Blocked & Pro-democracy \\
\hline http://www.geocities.com/CapitolHill/7288/ & $\mathrm{N} / \mathrm{A}$ & Blocked & Pro-democracy \\
\hline http://www.geocities.com/CapitolHill/6901/index.html & $\mathrm{N} / \mathrm{A}$ & Blocked & Pro-democracy \\
\hline http://www.freechina.net/pfdc/ & $\mathrm{N} / \mathrm{A}$ & Blocked & Pro-democracy \\
\hline Total (2o sites) & $80 \%$ & $89 \%$ & \\
\hline
\end{tabular}

\section{Taiwan}

We tested sites containing general information on Taiwan as well as those advocating independence from China. While our proxy testing found an extremely high level of blocking, in-state testing revealed a more moderate picture, with half of the tested sites blocked. The home page of the Taiwanese government was found blocked in both tests, as was the page of an organization committed to 
independence from China. The Taipei Times was not blocked in either test, although the proxy we tested was unable to reach its content through a different site.

Figure 6 - Taiwan Sites

\begin{tabular}{|l|c|c|}
\hline Sites Tested & $\begin{array}{c}\text { In-State } \\
\text { Result }\end{array}$ & $\begin{array}{c}\text { Proxy } \\
\text { Result }\end{array}$ \\
\hline http://www.taipeitimes.com/ & Accessible & Accessible \\
\hline $\begin{array}{l}\text { http://www.theworldpress.com/press/worldpress/ } \\
\text { taiwanpress/taipeitimes.htm }\end{array}$ & Accessible & Blocked \\
\hline http://www.roc-taiwan.org/ & Accessible & N/A \\
\hline http://www.gov.tw/ & Blocked & Blocked \\
\hline http://www.taiwan.com/ & Blocked & Blocked \\
\hline http://www.taiwanindependence.com/ & Blocked & Blocked \\
\hline http://anti-china.net/ & N/A & Blocked \\
\hline http://cti.formosa.org/ & N/A & Blocked \\
\hline http://en.wikipedia.org/wiki/Taiwan_independence & N/A & Blocked \\
\hline http://members.aol.com/JoJoLewis/Taiwan/Taiwan_index.html & N/A & Blocked \\
\hline http://taiwansecurity.org/ & N/A & Blocked \\
\hline http://www.taiwandc.org/nws-9845.htm & N/A & Blocked \\
\hline http://www.taiwanese.com/protest/ & N/A & Blocked \\
\hline http://www.wufi.org.tw/eng/chnamyth.htm & N/A & Blocked \\
\hline Total (14 sites) & $\mathbf{5 0 \%}$ & $\mathbf{9 2 \%}$ \\
\hline
\end{tabular}

\section{Tibet}

China blocked significant amounts of content in this category, including both material concerning the dispute over Tibet and sites about the Dalai Lama himself. Again, our proxy testing found more comprehensive blocking; in-state testing found www.tibet.com, the official home page of Tibet's government in exile, available. Although the other accessible sites, one about the Dalai Lama's 2005 trip to Belgium and one based on an extensive 1996 interview, may have proved difficult for China to locate and subsequently block, the same can hardly be true for www.tibet.com. Its accessibility suggests an inconsistency in the operation of China's filtering; further in-state data will hopefully clarify this picture. 
Figure 7 - Tibet Sites

\begin{tabular}{|l|c|c|}
\hline Sites Tested & In-State Result & Proxy Result \\
\hline http://www.dalailama-belgium2005.org/ & Accessible & Accessible \\
\hline http://www.gluckman.com/DalaiLama.html & Accessible & Accessible \\
\hline http://www.tibet.com/ & Accessible & Blocked \\
\hline http://worldbridges.com/Tibet/ & Blocked & Blocked \\
\hline http://www.dalailama.com/ & Blocked & Blocked \\
\hline http://www.freetibet.org/ & Blocked & Blocked \\
\hline http://www.boycottmadeinchina.org/ & N/A & Blocked \\
\hline http://www.buyhard.fsnet.co.uk/boycottchinafortibet.htm & N/A & Blocked \\
\hline http://www.studentsforafreetibet.org/ & N/A & Blocked \\
\hline http://www.tibet.ca/en/ & N/A & Blocked \\
\hline http://www.tibetanliberation.org/ & N/A & Blocked \\
\hline http://www.tibetjustice.org/index.html & N/A & Blocked \\
\hline Total (12 sites) & & $\mathbf{5 0 \%}$ \\
\end{tabular}

\section{In-State Testing Results}

To analyze the experience that a typical Chinese user has when attempting to access Internet content, ONI had several volunteers run its distributed testing application from different access points within the country.

\section{Summary}

ONI's enumeration of China's filtering included two independent tests of 7929 URLs performed by volunteers at different access points within the country. Unlike other countries in which ONI has tested filtering, China does not present users who attempt to access disapproved content with a "block page"; rather, users simply cannot access the material and often receive a general error message. To identify instances where testers' inability to access a page was likely caused by China's filtering system, we defined sites as inaccessible due to blocking when two conditions were met:

1. Both of our testers were unable to reach the site, and

2. Both testers were, simultaneously, able to reach the site via a remote proxy server set up outside China for testing purposes.

The chart below summarizes our testing results. 
Figure 8 - Summary of In-State Testing Results

\begin{tabular}{|l|l|l|}
\hline Status & URLS & Percent \\
\hline Accessible Twice & 5271 & $66 \%$ \\
\hline Accessible Once & 699 & $9 \%$ \\
\hline Inaccessible Twice & 1959 & $25 \%$ \\
\hline Total & 7929 & \multicolumn{2}{|l}{} \\
\cline { 1 - 2 } & &
\end{tabular}

We treated URLs that were accessible once as accessible (not filtered) in our analysis.

To provide comparison, our testing included $813 \mathrm{Web}$ sites found within the .cn top-level domain. We assumed that these sites, which are in a top-level domain controlled by China, would not be filtered and would generally be accessible within China. The statistics for tested sites in .cn are below.

Figure 9 - In-State Testing Results for .cn Web Sites

\begin{tabular}{|l|l|l|}
\hline Status & URLs & Percent \\
\hline Accessible Twice & 730 & $90 \%$ \\
\hline Accessible Once & 83 & $10 \%$ \\
\hline Inaccessible Twice & - & - \\
\hline Total & 813 & \multicolumn{1}{|c|}{} \\
\cline { 1 - 2 } & &
\end{tabular}

These results support our definition of inaccessibility due to filtering; countries generally do not use technical means to filter content that is within their top-level domain, since they can exercise more direct forms of control over this material.

\section{Long List Results}

To explore further the accessibility of Web sites containing content potentially sensitive to China, we created a testing list (the "long list") containing the top 100 sites returned by the Google search engine for queries on Chinese and English keywords related to sensitive topics, such as "Falun Gong." The charts below report the results of in-state testing of this long list, divided by topic area. This data represents the percentage of the sites on the long list that testers could not access (we defined a site as inaccessible if it could not be reached in two or more test runs). 
a. Falun Gong Sites

Figure 10 - Falun Gong Google Results

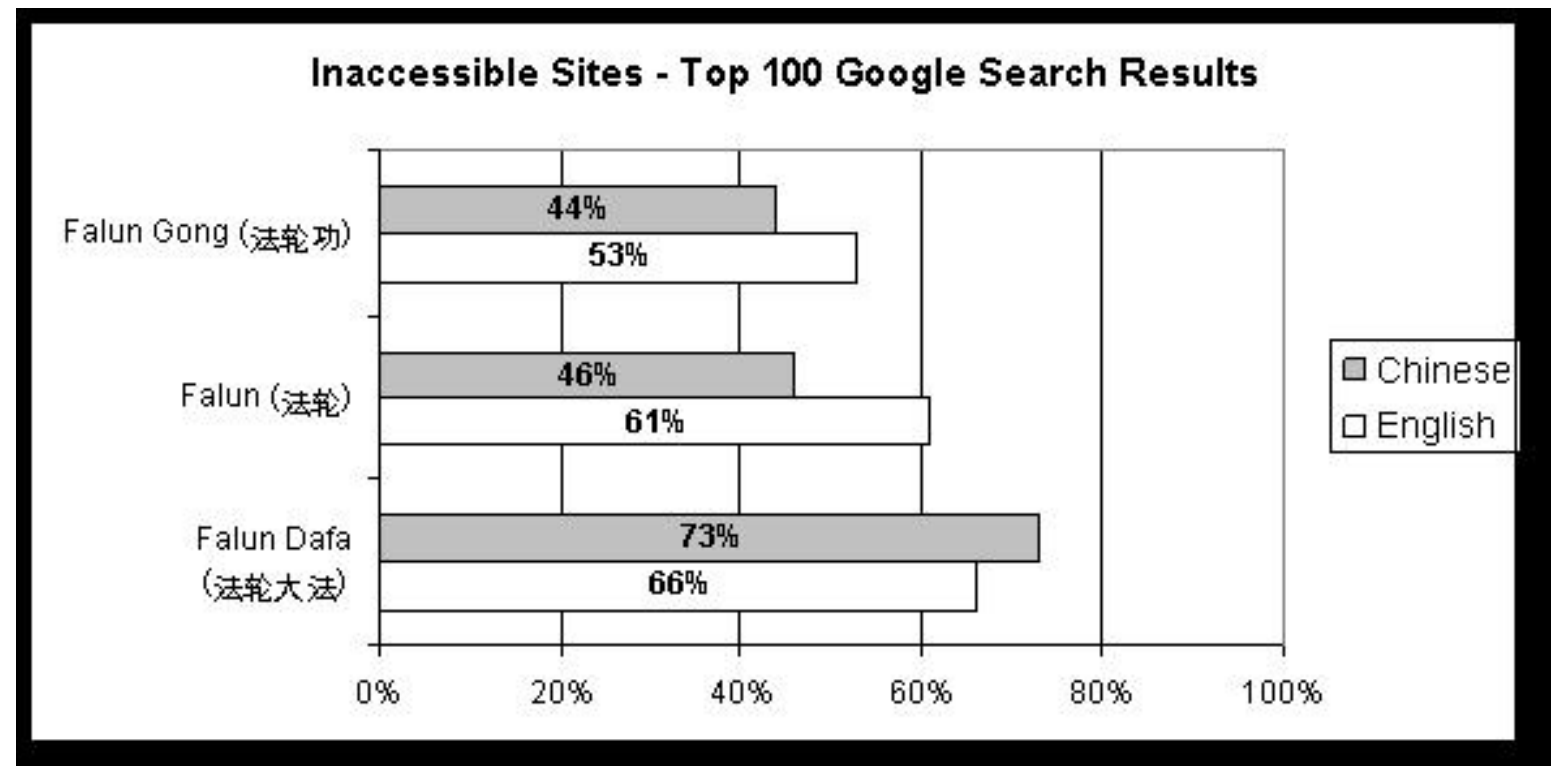

Our testing found a significant number of sites relating to the Falun Gong spiritual movement inaccessible. Unlike in many other categories of content, a significant percentage of the English language sites were blocked, in both absolute terms and relative to Chinese language sites. 


\section{b. General Political Content}

Figure 11 - Political Content Google Results

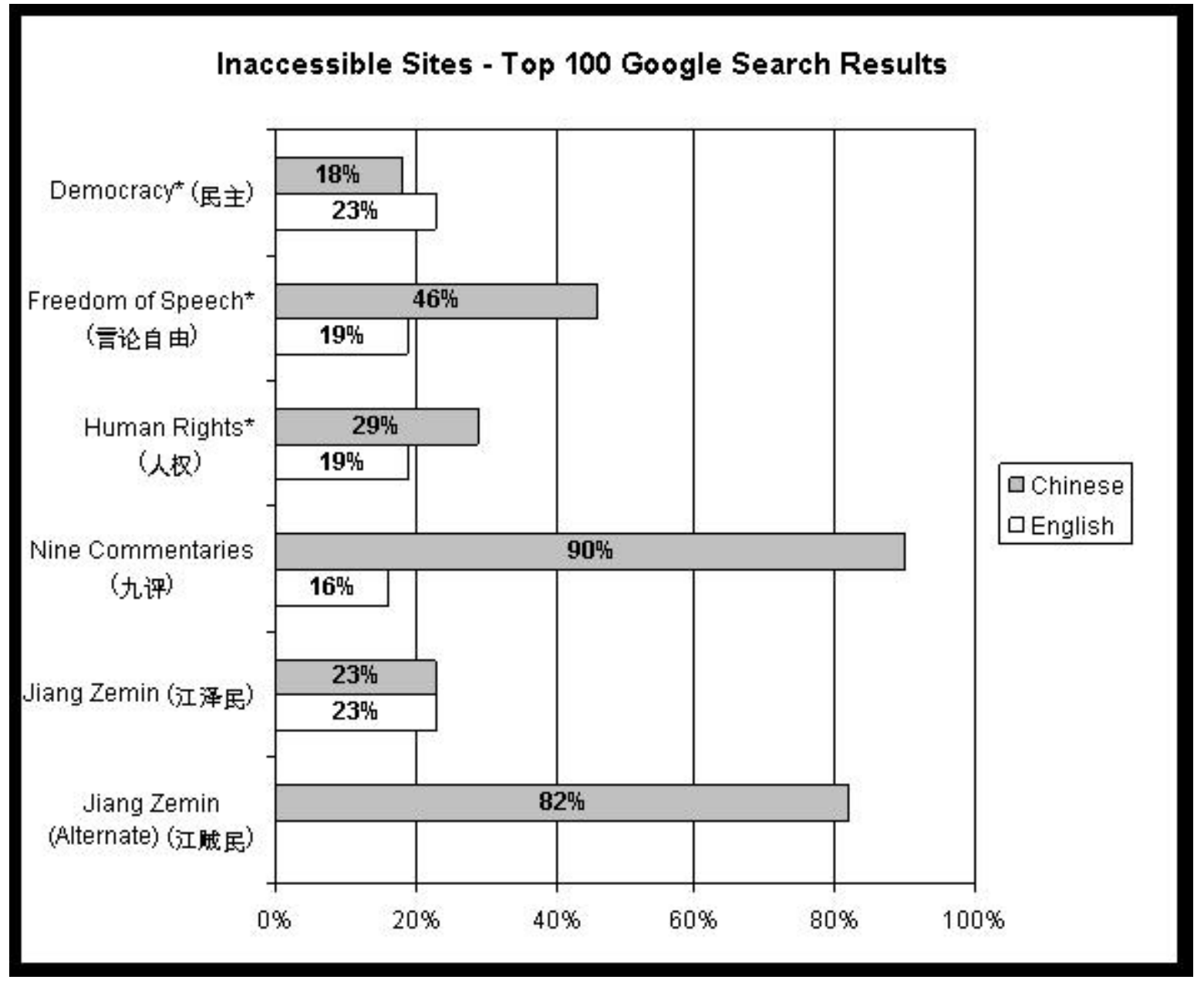

* We added "China" to the English term when conducting the Google search to focus the results.

These results demonstrate moderate inaccessibility of English and Chinese language sites for the general terms "democracy," "human rights," and "Jiang Zemin." We performed a search for a common variation of Jiang Zemin's name used in criticism and satire by "replacing one of the characters of his name by the character for "thief." 154 Tested Chinese language sites with this variation were almost completely inaccessible (we could not run this search in English since it depends on the similarity of the terms in Chinese). Sites listed in response to a search for the "Nine Commentaries," a highly critical evaluation of the Chinese Communist Party published by the Epoch Times, were also nearly totally

154 OpenNet Initiative, Filtering by Domestic Blog Providers in China, Jan. 14, 2005, available at http://www.opennetinitiative.net/bulletins/008/. 
inaccessible. ${ }^{155}$ Interestingly, testers were able to access English language sites for this term significantly more often, due in part to a number of sites offering "nine commentaries" on other topics (such as the architect Frank Lloyd Wright). This may also demonstrate lesser concern by China for English language material on the Nine Commentaries.

\section{c. Opposition Political Parties}

\section{Figure 12 - Opposition Political Party Google Results}

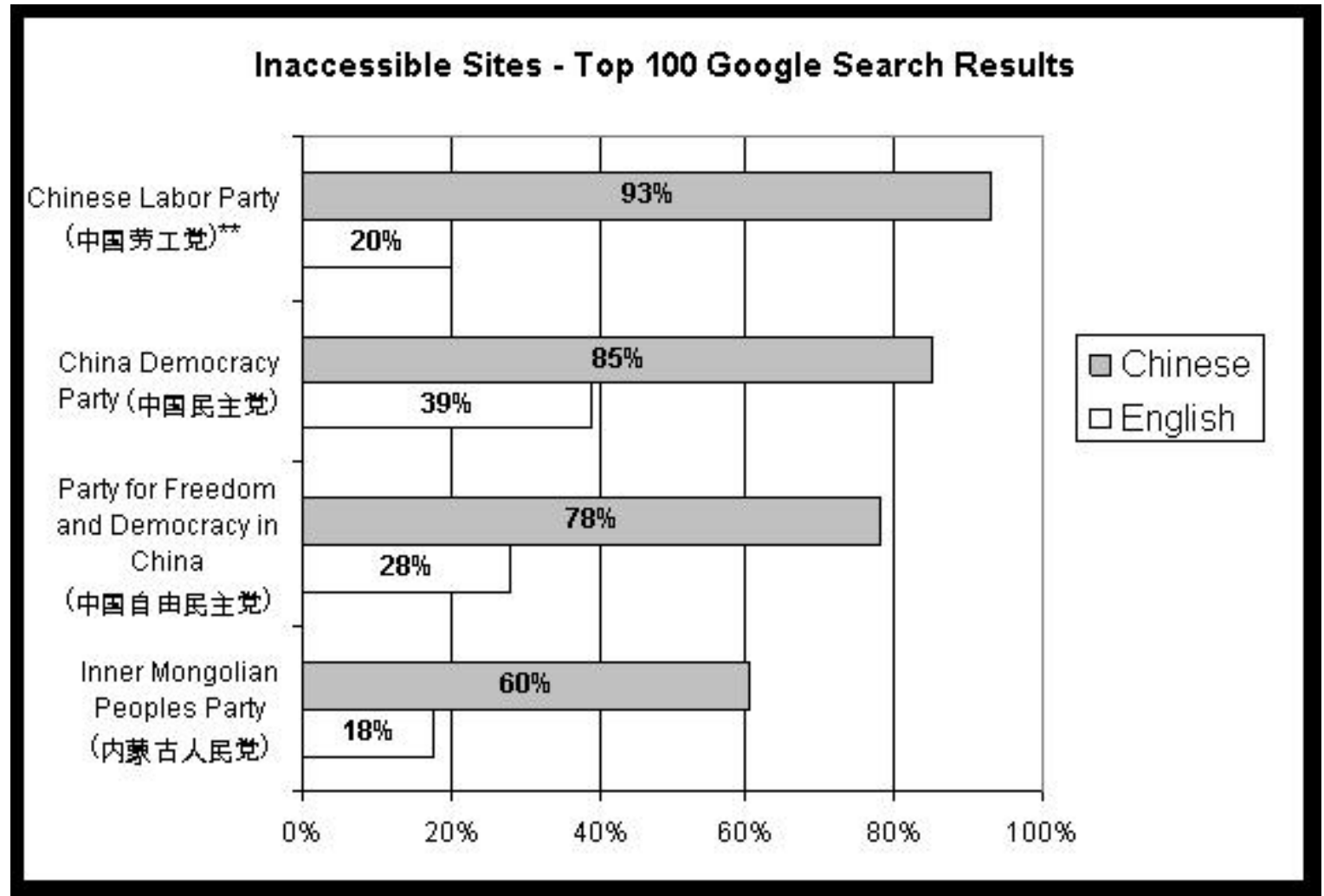

** We tested multiple translations of this phrase, and used this particular search term because Google returned the greatest number of results in response to the query for it as compared to other variations.

Chinese language Web sites pertaining to opposition political parties were inaccessible during instate testing with extremely high frequency. In some cases, such as URLs related to the Chinese Labor Party, sites were almost completely filtering during our testing. We again found moderate to significant levels of inaccessibility for English language sites related to opposition parties.

155 See The Epoch Times, Nine Commentaries on the Communist Party, Dec. 1, 2004, available at http://english.epochtimes.com/news/4-12-1/24696.html. 


\section{d. Tiananmen Square}

Figure 13 - Tiananmen Square Google Results

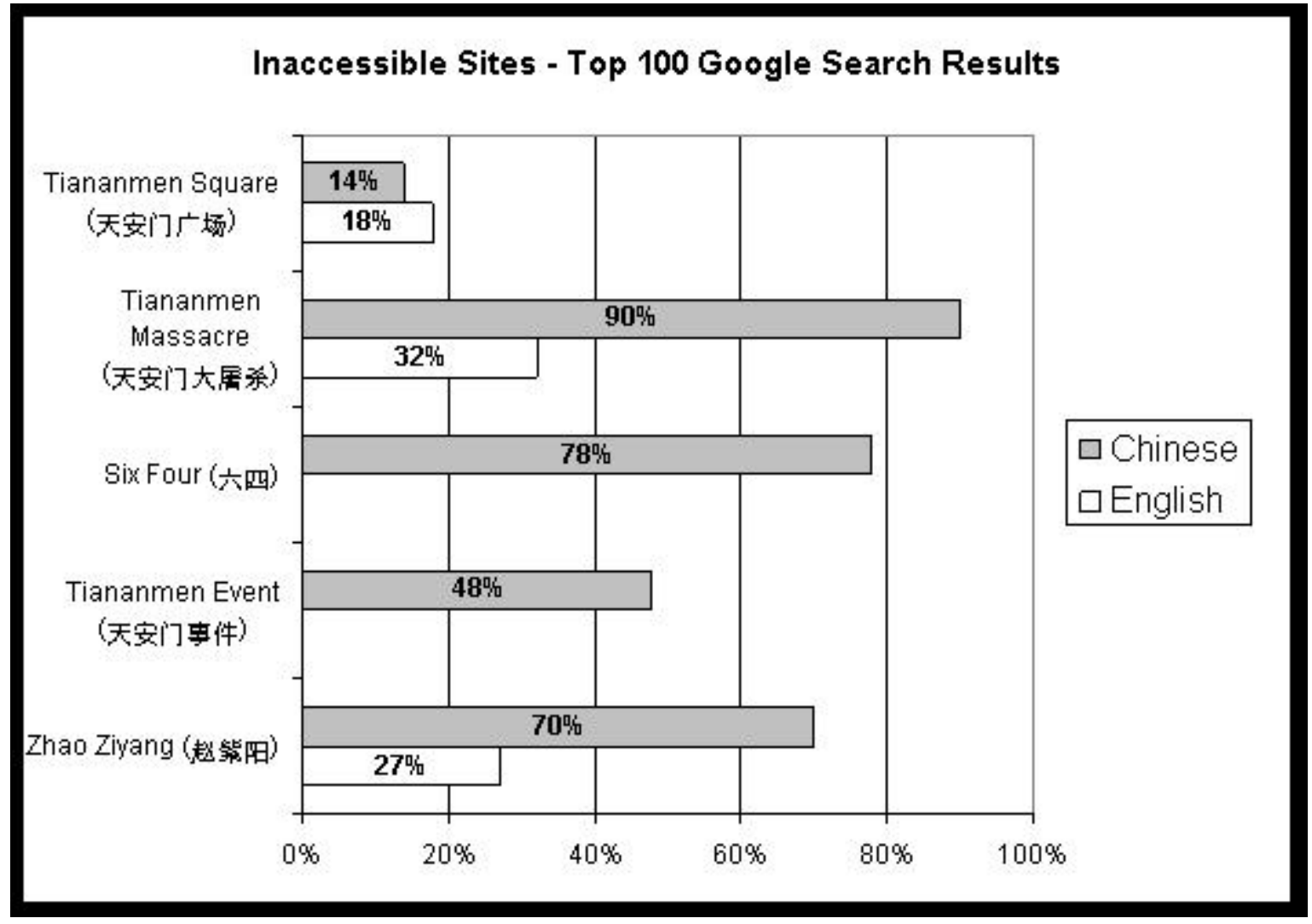

ONI's testing found wide variation in whether sites on the Tiananmen Square incident could be accessed, depending on the search term used. Chinese language sites related to searches for politically sensitive descriptions, such as "massacre" and "six four," were virtually inaccessible during our testing; we found moderate levels of inaccessibility for English language sites pertaining to the search term "Tiananmen massacre" (we did not test the terms "six four" or "Tiananmen event" in English since they generated too many unrelated sites). We found filtering of $70 \%$ of Chinese language sites related to a search for Zhao Ziyang, the former leader of China's Communist Party who was removed from his post for opposing the repression of the Tiananmen demonstrations. Surprisingly, URLs listed in response to a search for "Tiananmen Square" itself were only moderately inaccessible for both Chinese and English language sites. 


\section{e. Independence Movements}

Figure 14 - Independence Movement Google Results

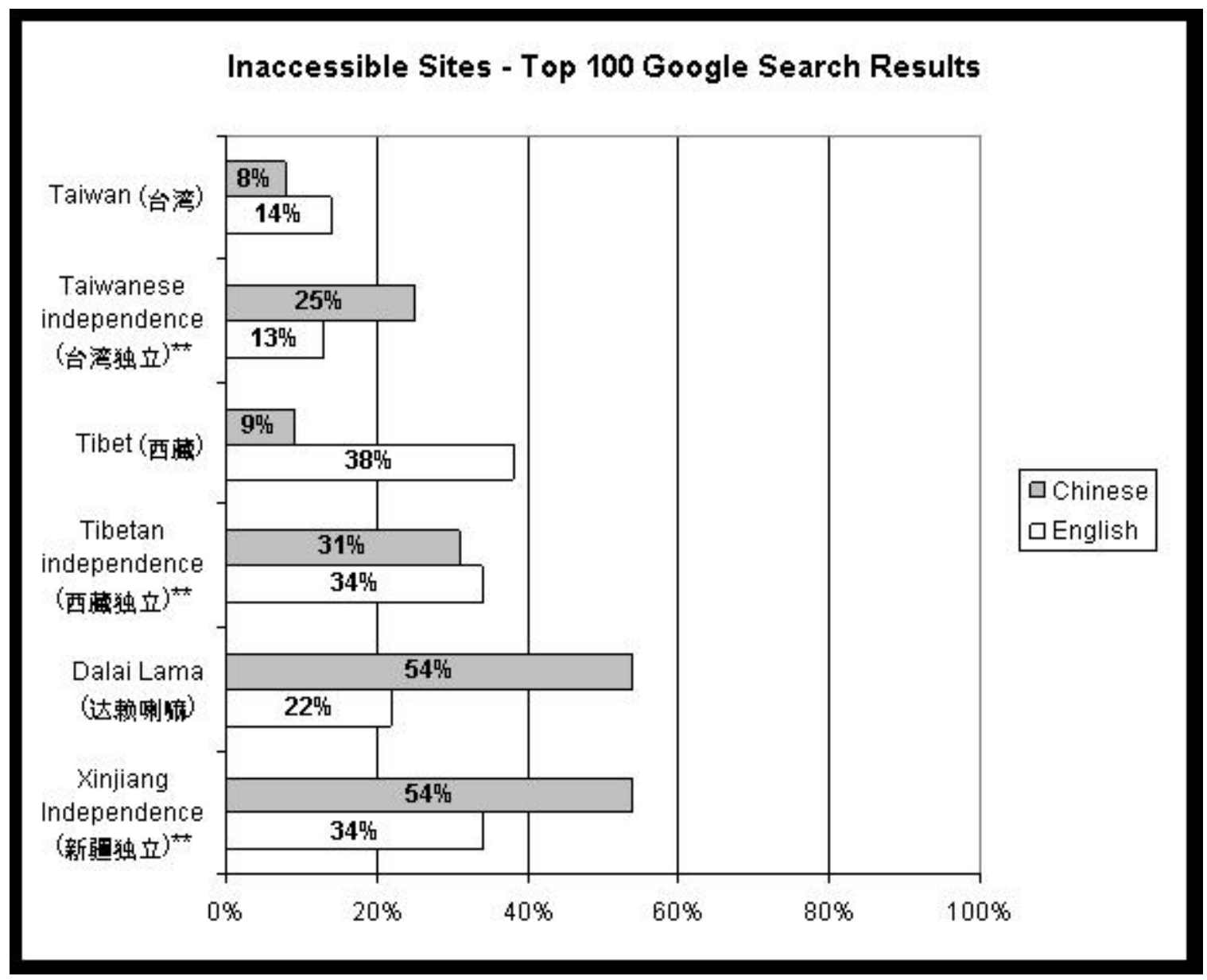

** We tested multiple translations of this term, with substantially similar results.

Sites on these topics were accessible more often than sites in other categories, though testers were not able to reach the majority of Chinese language sites concerning the Dalai Lama and Xinjiang independence.156 A relatively small percentage of Chinese language sites listed for searches for "Tibet" and "Taiwan" were inaccessible; the number rose significantly when the search query included the term "independence." Chinese language sites related to Tibet were slightly less accessible than sites discussing Taiwan; this gap was more pronounced for English language search results.

${ }^{156}$ See generally Howard W. French, China Moves Toward Another West: Central Asia, N.Y. Times, Mar. 28, 2004, at 1 (describing China's concerns about the "threat of separatism by the region's Uighur minority, whose Turkik language and Islamic faith draw them toward kinsmen in Kazakhstan and other former Soviet republics of the region"); see also You Ji, China's post 9/11 terrorism strategy, Ass'n for Asian Research, May 11, 2004, at http://www.asianresearch.org/articles/2047.html. 


\section{f. Sex}

Figure 15 - Sex Google Results

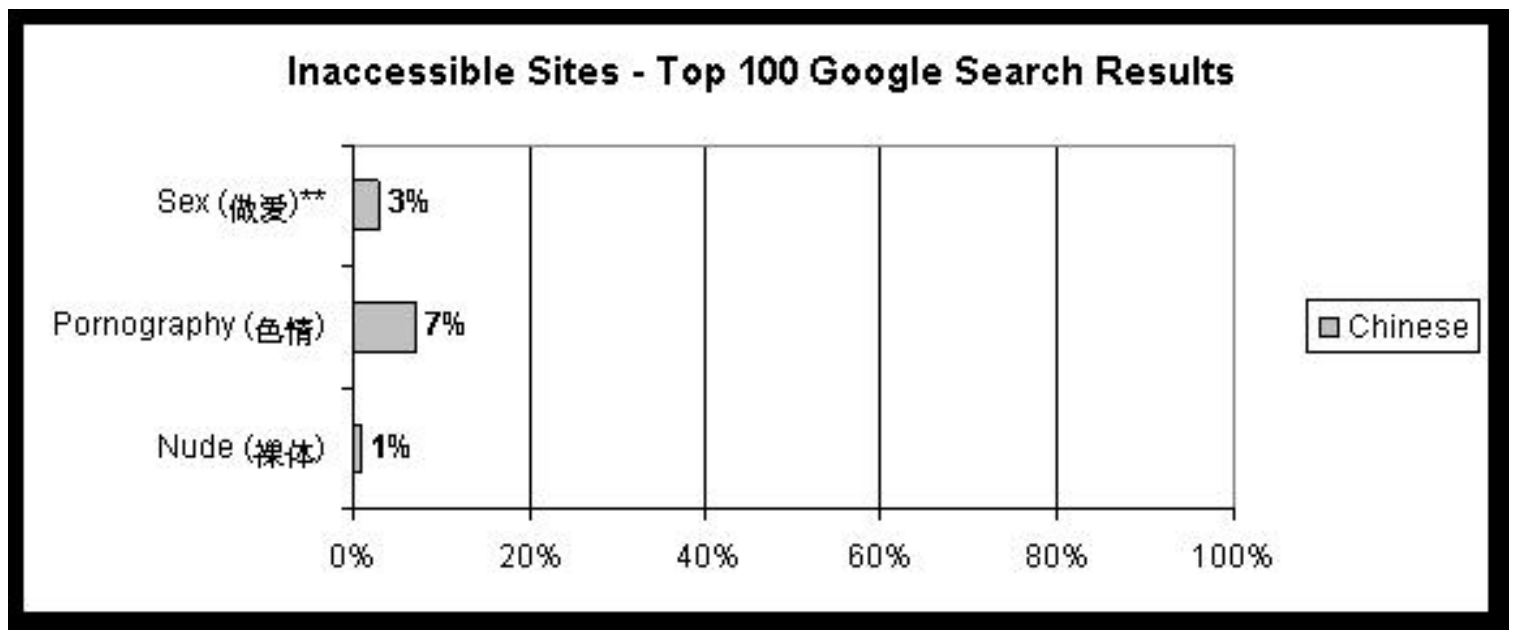

** We tested multiple translations of this term, with substantially similar results.

We tested only Chinese language terms related to sex, and found minimal inaccessibility. (Note that these results differ from those in our global list testing, described below, which found significant blocking of pornographic sites.)

\section{g. Homosexuality}

Figure 16- Homosexuality Google Results

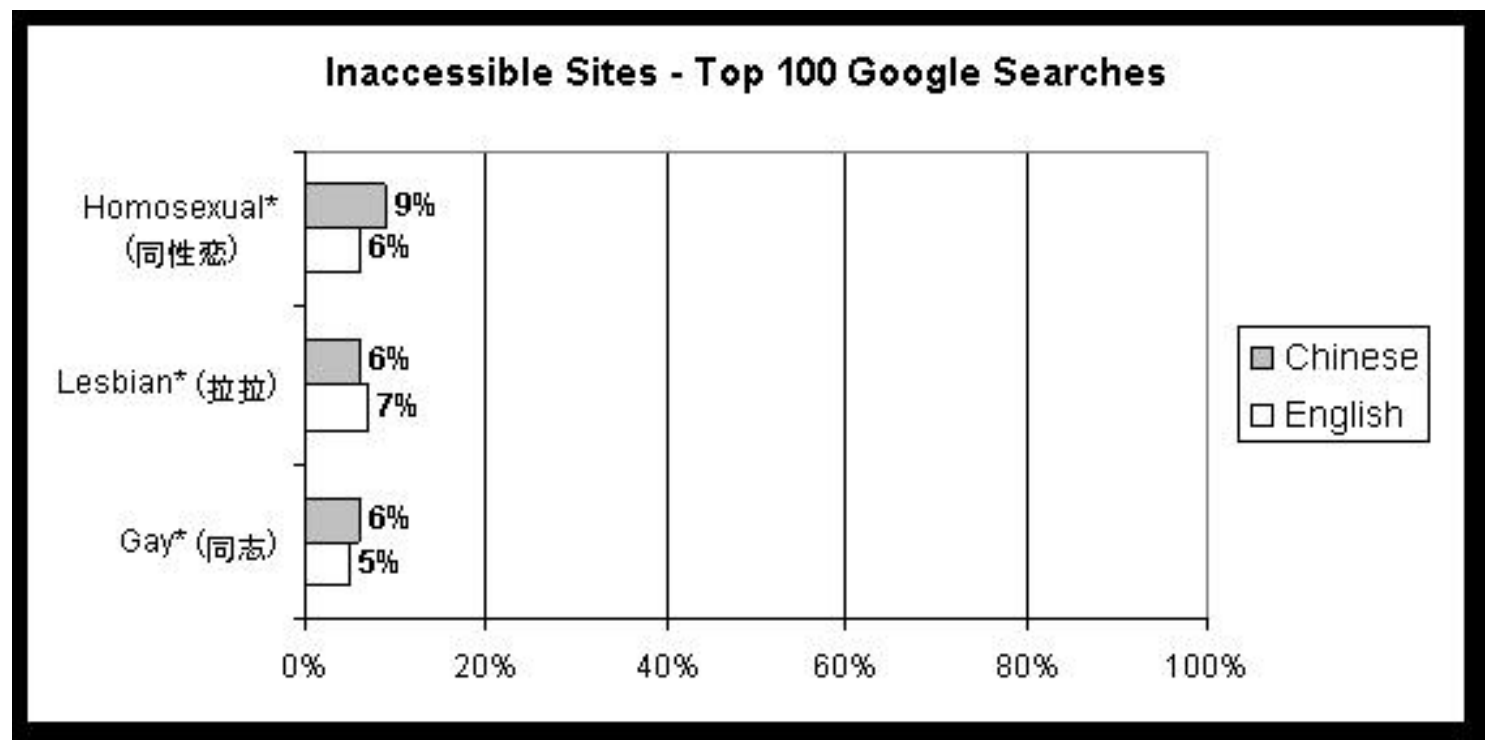


* We added "China" to the English search term when conducting the query to focus the search results.

Sites corresponding to both English and Chinese language search terms for this topic were only minimally inaccessible, although slightly more so than for general sex sites. This low level of inaccessibility is generally consistent with the inadvertent "overblocking" of sites that is a common side effect of large-scale filtering efforts.

\section{h. Longitudinal Comparison with 2002 Testing}

To analyze changes in China's filtering system over time, we compared our in-country results for sites related to a number of search terms in 2005 with results from ONI's testing in fall 2002. Several interesting trends appear in the data.

Figure 17 - Longitudinal Comparison - 2002 and 2005

\begin{tabular}{|c|c|c|c|c|}
\hline \multicolumn{5}{|c|}{ Proportion of Top 10 and Top 100 Google Search Results Inaccessible } \\
\hline & \multicolumn{2}{|c|}{ March - April 2005} & \multicolumn{2}{|c|}{ August - September 2002} \\
\hline Term & Top 10 Sites & Top 100 Sites & Top 10 Sites & Top 10o Sites \\
\hline china blog & $0 \%$ & $5 \%$ & $30 \%$ & $11 \%$ \\
\hline democracy China & $30 \%$ & $23 \%$ & $80 \%$ & $42 \%$ \\
\hline dissident & $10 \%$ & $14 \%$ & $60 \%$ & $31 \%$ \\
\hline dissident china & $50 \%$ & $28 \%$ & $80 \%$ & $37 \%$ \\
\hline equality & $0 \%$ & $3 \%$ & $100 \%$ & $24 \%$ \\
\hline freedom china & $20 \%$ & $23 \%$ & $60 \%$ & $32 \%$ \\
\hline revolution & O\% & $5 \%$ & $70 \%$ & $21 \%$ \\
\hline Taiwan & $10 \%$ & $14 \%$ & $70 \%$ & $47 \%$ \\
\hline Tibet & $60 \%$ & $38 \%$ & $100 \%$ & $64 \%$ \\
\hline 天安门事件 (Tiananmen Event) & $30 \%$ & $48 \%$ & $0 \%$ & $8 \%$ \\
\hline 性病 (STDs) & $0 \%$ & $1 \%$ & $60 \%$ & $13 \%$ \\
\hline 性病 中国 (STDs China) & $0 \%$ & $1 \%$ & $0 \%$ & $4 \%$ \\
\hline 民主 (democracy) & $30 \%$ & $18 \%$ & $40 \%$ & $15 \%$ \\
\hline 法轮功 (Falun Gong) & $40 \%$ & $44 \%$ & $30 \%$ & $15 \%$ \\
\hline
\end{tabular}

The clearest trend is that sites are, generally, more accessible in 2005 than in 2002. Only sites related to the Chinese terms for "Falun Gong" and "Tiananmen Event" were consistently less accessible in 2005. We found what appears to be greater specificity and better targeting by China's filtering system: the largest declines in inaccessibility were for sites related to relatively vague English language search terms, such as "revolution" and "equality." Similarly, sites returned in response to search engine queries for the keywords "Taiwan" and "Tibet" were substantially less inaccessible in 2005 than 2002. One plausible explanation is that China has refined its filtering system in the intervening 3 years. For 
example, sites related to searches for the terms "Tibet independence" and "Taiwan independence" were three times as inaccessible as sites for "Tibet" and "Taiwan" alone. This suggests that China has tuned its filters to allow access to more neutral content on these general topics while preventing access to more politically sensitive material.

\section{Global List Results}

Figure 18 - Global List Testing Results

\begin{tabular}{|c|c|c|c|}
\hline Category & $\begin{array}{c}\text { Sites } \\
\text { Tested }\end{array}$ & $\begin{array}{c}\text { Percent } \\
\text { Inaccessible }\end{array}$ & Inaccessible Sites \\
\hline Alcohol & 21 & $0 \%$ & \\
\hline Anonymizers & 20 & $5 \%$ & www.anonymizer.com \\
\hline Blogging Domains & 19 & $5 \%$ & www.tblog.com \\
\hline Drugs & 27 & $0 \%$ & \\
\hline Email & 20 & $10 \%$ & mail.yahoo.ca; www.volcanomail.com \\
\hline Encryption & 10 & O\% & \\
\hline Entertainment & 27 & $0 \%$ & \\
\hline Famous Bloggers & 23 & $13 \%$ & $\begin{array}{l}\text { dear_raed.blogspot.com; oxblog.blogspot.com; } \\
\text { atrios.blogspot.com }\end{array}$ \\
\hline Filtering Sites & 9 & $11 \%$ & www.rsf.org \\
\hline Free Web Space & 11 & $27 \%$ & $\begin{array}{l}\text { www.150m.com; www.envy.nu; } \\
\text { www.fortunecity.com }\end{array}$ \\
\hline Gambling & 25 & $8 \%$ & www.allcraps.com; www.poker.com \\
\hline $\begin{array}{l}\text { Gay/Lesbian/Bisexual } \\
\text { /Transgender/Queer }\end{array}$ & 38 & $11 \%$ & $\begin{array}{l}\text { www.al-fatiha.net; www.amnestyusa.org/outfront; } \\
\text { www.gayegypt.com; www.lgbt.com }\end{array}$ \\
\hline Government & 56 & $5 \%$ & $\begin{array}{l}\text { www.misrnet.idsc.gov.eg; www.president.gov.tw; } \\
\text { www.tibet.com }\end{array}$ \\
\hline $\begin{array}{l}\text { Groups (including } \\
\text { usenet) }\end{array}$ & 17 & $6 \%$ & groups.google.com \\
\hline Hacking & 22 & $5 \%$ & www.cultdeadcow.com \\
\hline Hate Speech & 24 & $13 \%$ & $\begin{array}{l}\text { www.aryannations.org; www.nsm88.com; } \\
\text { www.resistance-radio.com }\end{array}$ \\
\hline Human Rights & 27 & $7 \%$ & www.amnesty.org; www.rsf.org \\
\hline Humor & 19 & $0 \%$ & \\
\hline Major Events & 29 & $14 \%$ & $\begin{array}{l}\text { www.falundafa.org; www.passionofthepresent.org; } \\
\text { www.tibet.org; www.tsquare.tv }\end{array}$ \\
\hline
\end{tabular}




\begin{tabular}{|l|r|r|l|}
\hline Misc & 11 & $0 \%$ & \\
\hline News Outlets & 35 & $6 \%$ & news.bbc.co.uk; www.chinatimes.com.tw \\
\hline Porn & 38 & $39 \%$ & [various] \\
\hline Provocative Attire & 17 & $6 \%$ & www.abcunderwear.com \\
\hline Religion (fanatical) & 9 & $0 \%$ & \\
\hline Religion (normal) & 51 & $2 \%$ & www.nobeliefs.com \\
\hline Search Engines & 27 & $7 \%$ & www.afghana.com; www.yahooligans.com \\
\hline Sex Ed & 26 & $8 \%$ & www.kidstalkaids.org; www.premaritalsex.info \\
\hline Translation Sites & 13 & $0 \%$ & \\
\hline Universities & 33 & & \\
\hline Weapons/Violence & 28 & $4 \%$ & \\
\hline Women's Rights & 29 & www.guncite.com & www.ifeminists.com; www.womenofarabia.com \\
\hline
\end{tabular}

The results from ONI's in-country testing of our global list contain several interesting findings. First, the anonymizer sites that allow users to circumvent filtering were almost fully accessible in China. This is in sharp contrast to the practice of most countries with sophisticated filtering regimes, who aggressively block these sites.

Second, three popular free Web hosting domains are inaccessible, along with groups.google.com. This suggests that China is willing to block all content in these domains - even unrelated, inoffensive material -- and not simply content targeted by the state as prohibited. The inaccessibility of the three blogs hosted on blogspot.com suggests a similar approach to blogs: tolerating broad overblocking to control sensitive content.

Third, pornography is inaccessible at a relatively high rate. ${ }^{157}$ This result contrasts with the low inaccessibility rate for sites returned from a Chinese language search for the term "pornography," as described above.

Fourth, our testing revealed a significant number of sites that are inaccessible despite the availability of similar content at other Web pages (for example, see the sites that are blocked and available in the global list's "weapons/violence" and "religion(normal)" categories). Some of the inaccessible sites are those known to be targeted specifically by China's filtering, such as news.bbc.co.uk, www.amnesty.org, and sites relating to Taiwan and Tibet. Many others, though, appear unrelated to China's filtering goals as we understand them. It is not currently clear whether this mix of available and inaccessible sites with

${ }^{157}$ China has sought to crack down on Internet pornography recently. See, e.g., China moves against Internet porn, BBC News.com, Aug. 1, 2004, at http://news.bbc.co.uk/2/hi/asia-pacific/3943445.stm. 
similar content indicates a limited degree of concern for material in these subject areas, or whether the inaccessible sites are simply an unintended by-product of China's filtering techniques.

Finally, and somewhat surprisingly, the majority of sites in the global list's "anonymizers," "human rights," and "news" sites were accessible during our testing. This finding contradicts the conventional wisdom about China's blocking practices, and lends support for our conclusion that China's filtering has become more finely targeted over time.

\section{Domain-specific Blocking}

Our in-state testing of the long list included multiple URLs in the same domain - for example, http://www.gluckman.com/DalaiLama.html and http://www.gluckman.com/Tianan.html. Filtering is often done at the domain level; thus, our previous studies generally find binary results: a domain is either completely accessible or completely inaccessible (with the frequent exception of domains that host a wide variety of content by different authors, such as free web hosts or blogging domains). Domains with a mixture of accessible and inaccessible URLs can help us understand the technical means employed to filter and can offer more detail on what content is targeted for filtering.

From a technical perspective, different results for sites in a single domain can result from either an inconsistent filtering system that does not subject all Web site requests to the same standards or the targeting of very specific content. Our results do not yet allow us to answer definitively which of these answers applies in the case of China.

\section{a. Partially and Completely Inaccessible Domains}

We tested 2 or more URLs for 1091 domains; our in-country testers could not access at least one URL in 297 of these domains (27\%). Of these 297, all URLs tested were inaccessible in 278 domains (94\%), and 19 (6\%) had both accessible and inaccessible URLs. Since the URLs we tested resulted from searches on keywords identified as potentially sensitive to the Chinese state, it is possible that other, untested URLs within these domains with non-sensitive content would have been available.

\section{i. Heavily Tested Domains}

The following domains had over 20 URLs tested, all of which were inaccessible in our testing.

\section{Figure 19 - Heavily Tested Domains With No Accessible URLs}

\begin{tabular}{|l|r|}
\hline \multicolumn{1}{|c|}{ Domain } & $\begin{array}{c}\text { Inaccessible } \\
\text { URLs }\end{array}$ \\
\hline http://news.bbc.co.uk & 81 \\
\hline http://www.geocities.com & 55 \\
\hline http://www.epochtimes.com & 46 \\
\hline http://www.boxun.com & 44 \\
\hline http://www.peacehall.com & 37 \\
\hline http://www.voanews.com & 29 \\
\hline http://www.rfa.org & 28 \\
\hline http://www.democracy.org.hk & 23 \\
\hline
\end{tabular}




\begin{tabular}{|l|r|}
\hline http://www.freechina.net & 21 \\
\hline http://xinsheng.net & 20 \\
\hline
\end{tabular}

\section{ii. Selected Other Domains}

These domains also had entirely inaccessible URLs in our testing.

Figure 20 - Selected Domains With No Accessible URLs

\begin{tabular}{|l|r|}
\hline \multicolumn{1}{|c|}{ Domain } & Inaccessible URLs \\
\hline http://web.amnesty.org & 5 \\
\hline http://www.amnesty.org & 4 \\
\hline http://www.amnesty.org.uk & 3 \\
\hline http://members.tripod.com & 13 \\
\hline http://members.lycos.co.uk & 10 \\
\hline http://www.angelfire.com & 8 \\
\hline http://hk.geocities.com & 5 \\
\hline http://www.salon.com & 4 \\
\hline http://[blogname].blogspot.com & 13 \\
\hline
\end{tabular}

iii. Selected Partially Accessible Domains

Figure 21 - Selected Domains With Some Accessible and Some Inaccessible URLs ${ }^{158}$

\begin{tabular}{|l|r|r|}
\hline \multicolumn{1}{|c|}{ Domain } & Inaccessible URLS & \multicolumn{1}{c|}{ Accessible URLs } \\
\hline http://members.aol.com & 4 & 8 \\
\hline http://www.fofg.org & 3 & 7 \\
\hline http://edition.cnn.com & 4 & 6 \\
\hline http://taiwansecurity.org & 2 & 6 \\
\hline http://www.asiaweek.com & 1 & 6 \\
\hline http://www.cnn.com & 16 & 2 \\
\hline http://www.time.com & 10 & 1 \\
\hline http://www.yale.edu & 3 & 1 \\
\hline http://www.gluckman.com & 2 & 1 \\
\hline
\end{tabular}

The cause for the mixed results in these domains is not always evident. Some results are easily explained: the accessible URL in the www.yale.edu domain was Yale University's home page, while the inaccessible URLs were related to the Falun Dafa (Falun Gong) movement, or to relations between China and Taiwan. However, there appears to be little semantic difference between accessible and inaccessible content in the www.fofg.org or edition.cnn.com domains. In addition, while most inaccessible URLs in the members.aol.com previously hosted content on the Inner Mongolian People's Party, an opposition political movement, there were inconsistent results for two different URLs leading to the same content:

${ }^{158}$ See Appendix 3 for a list of all URLs tested in these domains and their status (accessible or inaccessible). 
the URL http://members.aol.com/imppsite/ was accessible, while another URL resolving to the same page, http://members.aol.com/imppsite/index.htm, was not.

\section{b. Free Web Hosting and Blogging Domains}

Our results suggest that China frequently responds to the possibility that certain domains may contain a mix of targeted and unrelated content by rendering the entire domain inaccessible. Our incountry testing data provides numerous examples of this approach, including the domains www.geocities.com, www.angelfire.com, members.tripod.com, and the blogspot.com domains. Since these domains resulted from searches for keywords on subjects likely to be of concern to the Chinese state, these results may overstate the extent of domain-wide filtering. However, our testing of clearly nonsensitive content in the www.geocities.com domain (including puppetry and juggling sites) supports our conclusion about domain-level blocking. Additionally, 3 of the inaccessible blogspot.com URLs were derived from our global list, and thus were unlikely to contain material to which the Chinese state is particularly sensitive. ONI found independent reports that www.geocities.com and blogspot.com were previously reported as entirely inaccessible by Chinese users, strengthening our analysis here.159

\footnotetext{
159 See Paul Baranowski, Blogspot Now Blocked From China, Jan. 10, 2005, at http://www.peek-abooty.org/pbhtml/modules.php?name=News\&file=article\&sid=56; Benjamin Edelman, Blocked sites will return, but with limited access, South China Morning Press, Jan. 26, 2003, available at http://cyber.law.harvard.edu/people/edelman/pubs/scmp-012603/.
} 


\section{Overblocking}

As a component of our in-state and proxy testing, we sought to locate sites whose Uniform Resource Locator (URL) ${ }^{160}$ contained strings indicative of content generally targeted by China, yet whose actual content was unrelated to these topics. Our proxy testing located a high degree of such overblocking; the in-state testing located far less, but still contained several examples of sites blocked despite the lack of any material potentially offensive to China.

\section{Falun Gong}

URLs tested here included either of the strings "falu" or "flg." Proxy testing found 60\% of these sites blocked, although in-state testing found none.

\section{Figure 22 - Falun Gong Overblocking}

\begin{tabular}{|l|l|l|l|}
\hline Sites Tested & $\begin{array}{l}\text { In-State } \\
\text { Result }\end{array}$ & $\begin{array}{l}\text { Proxy } \\
\text { Result }\end{array}$ & Description \\
\hline http://www.redsalta.com/folclore/falu.htm & Accessible & Blocked & Eduardo Falu \\
\hline http://www.pitcher.no/FLG.html & Accessible & Blocked & $\begin{array}{l}\text { Computer utility (File List } \\
\text { Generator) }\end{array}$ \\
\hline http://www.falu.com/ & Accessible & Blocked & $\begin{array}{l}\text { Manufacturer of machines } \\
\text { to make cotton swabs }\end{array}$ \\
\hline http://www.flg.com/ & Accessible & Accessible & $\begin{array}{l}\text { Cargo transporting } \\
\text { company }\end{array}$ \\
\hline $\begin{array}{l}\text { http://www.multimediapalace.com/ } \\
\text { flg-wf.htm }\end{array}$ & Accessible & Accessible & \multicolumn{2}{|l}{} \\
\hline Total (5 sites) & $\mathbf{0 \%}$ & $\mathbf{6 0 \%}$ & \multicolumn{2}{|l}{} \\
\cline { 1 - 2 } & &
\end{tabular}

${ }^{160}$ See World Wide Web Consortium, Web Naming and Addressing Overview (UR/s, URLs, ...), available at http://www.w3.org/Addressing/ (last updated Feb. 17, 2005). 


\section{News}

We tested URLs containing the strings "bbc", "voa”, "voanews", "epoch”, and "peacehall.” Proxy testing found a majority of such sites blocked; in-state testing found a more limited set. Neither method included any blocks on URLs containing "epoch," but both found two of two URLS containing "voanews.com" blocked, although URLs containing only "voa" or "voanews" received mixed results.

Figure 23 - News Overblocking

\begin{tabular}{|c|c|c|c|}
\hline Sites Tested & In-State Result & Proxy Result & Description \\
\hline http://www.bbc.co.uk/ & Accessible & Accessible & $\begin{array}{l}\text { Home Page for BBC } \\
\text { Network, UK }\end{array}$ \\
\hline http://www.deckyard.com/epoch.htm & Accessible & Accessible & Deck repair \\
\hline http://www.epoch-net.org/ & Accessible & Accessible & $\begin{array}{l}\text { Excellence in } \\
\text { Processing Open } \\
\text { Cultural Heritage }\end{array}$ \\
\hline http://www.fortnet.org/VOA/ & Accessible & Accessible & $\begin{array}{l}\text { Volunteers of } \\
\text { America, Colorado }\end{array}$ \\
\hline $\begin{array}{l}\text { http://www.scifi.com/onair/ } \\
\text { scifipictures/epoch/ }\end{array}$ & Accessible & Accessible & Science Fiction film \\
\hline http://www.bloggerheads.com/bbc/ & Accessible & Blocked & $\begin{array}{l}\text { Supporting BBC } \\
\text { after the Hutton } \\
\text { Report }\end{array}$ \\
\hline http://www.peacehall.org/ & Accessible & Blocked & $\begin{array}{l}\text { The Peasall Sisters } \\
\text { Bluegrass Band }\end{array}$ \\
\hline $\begin{array}{l}\text { http://www.penkridge.org.uk/peaceh } \\
\text { all.htm }\end{array}$ & Accessible & Blocked & $\begin{array}{l}\text { Village hall in } \\
\text { Penkridge, UK }\end{array}$ \\
\hline $\begin{array}{l}\text { http://www.robbooth.net/2003/07/v } \\
\text { oanews.shtml }\end{array}$ & Accessible & Blocked & $\begin{array}{l}\text { Blog with link to } \\
\text { VOA Story }\end{array}$ \\
\hline http://www.voa-gny.org/ & Accessible & Blocked & $\begin{array}{l}\text { Volunteers of } \\
\text { America, Greater } \\
\text { New York }\end{array}$ \\
\hline http://massbird.org/bbc/ & Accessible & $\mathrm{N} / \mathrm{A}$ & $\begin{array}{l}\text { Brookline, MA bird } \\
\text { club }\end{array}$ \\
\hline $\begin{array}{l}\text { http://public.planetmirror.com/pub/ } \\
\text { abit/download/drivers_update/voane } \\
\text { ws.com/ }\end{array}$ & Blocked & Blocked & $\begin{array}{l}\text { Driver download; } \\
\text { no substantive } \\
\text { content }\end{array}$ \\
\hline $\begin{array}{l}\text { http://www.poets4peace.com/peaceh } \\
\text { all.htm }\end{array}$ & Blocked & Blocked & $\begin{array}{l}\text { "Hall of Peace" at } \\
\text { Poets4Peace.com }\end{array}$ \\
\hline $\begin{array}{l}\text { http://www.stumbleupon.com/url/w } \\
\text { ww.voanews.com/ }\end{array}$ & Blocked & Blocked & $\begin{array}{l}\text { Reviews of the VOA } \\
\text { News page }\end{array}$ \\
\hline http://www.lnx-bbc.org/ & Blocked & $\mathrm{N} / \mathrm{A}$ & Linux distribution \\
\hline Total (15 sites) & $27 \%$ & $62 \%$ & \\
\hline
\end{tabular}




\section{Political Topics}

Our results show minimal overblocking in this category; one of three sites tested containing the string "64" (corresponding to the June 4th date of Tiananmen Square) was blocked in proxy testing but not in-state, and neither of the URLs we tested containing "hric" (the acronym for Human Rights in China) was blocked in either method.

Figure 24 - Political Topic Overblocking

\begin{tabular}{|c|c|c|c|}
\hline Sites Tested & $\begin{array}{l}\text { In-State } \\
\text { Result }\end{array}$ & $\begin{array}{l}\text { Proxy } \\
\text { Result }\end{array}$ & Description \\
\hline http://www.ai-cit.sk/people/PhD/hric/ & Accessible & $\mathrm{N} / \mathrm{A}$ & Marcel Hric, PhD student \\
\hline http://www.neural.it/nnews/sixfour.htm & Accessible & $\mathrm{N} / \mathrm{A}$ & Italian hactivism \\
\hline http://www.x86-64.org/ & Accessible & Blocked & Open Source software \\
\hline http://www.hric.org/ & Accessible & Accessible & $\begin{array}{l}\text { Human Resources } \\
\text { Independent Consultants }\end{array}$ \\
\hline http://www.centre-square.com/ & Accessible & Accessible & $\begin{array}{l}\text { Theater in Ontario, } \\
\text { Canada }\end{array}$ \\
\hline http://www.hr.duke.edu/hric/ & Accessible & Accessible & Duke Human Resources \\
\hline http://www.hoobly.com/members/tsquare/ & Accessible & Accessible & Classified Ads \\
\hline http://www.bartleby.com/64/ & Accessible & Accessible & $\begin{array}{l}\text { English-language } \\
\text { reference }\end{array}$ \\
\hline $\begin{array}{l}\text { http://www.macminute.com/2004/12/23/ } \\
\text { 64-bit/ }\end{array}$ & Accessible & Accessible & Computer development \\
\hline Total (9 sites) & $\mathbf{o \%}$ & $14 \%$ & \\
\hline
\end{tabular}

4. Taiwan

Similar to the above categories, we found evidence of overblocking only in our proxy testing.

Figure 25 - Taiwan Overblocking

\begin{tabular}{|l|l|l|l|}
\hline Sites Tested & $\begin{array}{l}\text { In-State } \\
\text { Result }\end{array}$ & $\begin{array}{l}\text { Proxy } \\
\text { Result }\end{array}$ & Description \\
\hline $\begin{array}{l}\text { http://english.people.com.cn/data/province/ } \\
\text { taiwan.html }\end{array}$ & Accessible & Blocked & $\begin{array}{l}\text { Chinese government } \\
\text { site on "Taiwan } \\
\text { Province" }\end{array}$ \\
\hline $\begin{array}{l}\text { http://www.askaroo.com/info/ } \\
\text { Taiwanindependence.html }\end{array}$ & Accessible & Blocked & $\begin{array}{l}\text { Page lacks any } \\
\text { substantive content }\end{array}$ \\
\hline $\begin{array}{l}\text { http://www.lonelyplanet.com/destinations/ } \\
\text { north_east_asia/taipei/ }\end{array}$ & Accessible & Accessible & Travel guide to Taipei \\
\hline Total (3 sites) & $\mathbf{0 \%}$ & $\mathbf{6 7 \%}$ & \multicolumn{2}{|r}{} \\
\cline { 1 - 2 } & &
\end{tabular}




\section{Tibet}

We tested several URLs containing the strings "tibet” or "dalai". All were blocked in proxy testing; only a Swiss travel guide was blocked during in-state testing.

Figure 26 - Tibet Overblocking

\begin{tabular}{|l|c|c|l|}
\hline Sites Tested & $\begin{array}{l}\text { In-State } \\
\text { Result }\end{array}$ & $\begin{array}{l}\text { Proxy } \\
\text { Result }\end{array}$ & Description \\
\hline http://www.tibet.cn/ & Accessible & Blocked & China Tibet information center \\
\hline http://www.dalai.com/ & Accessible & Blocked & Dalai software, Mexico \\
\hline http://www.pmgeiser.ch/tibet/ & Blocked & Blocked & Tibet travel guide \\
\cline { 1 - 3 } Total (3 sites) & $\mathbf{3 3 \%}$ & $\mathbf{1 0 0 \%}$ & \multicolumn{2}{|l}{} \\
\cline { 1 - 2 } & \multicolumn{2}{|l}{} &
\end{tabular}

\section{E. Mechanics of China's Filtering}

Our results elucidate several interesting characteristics of how the underlying filtering infrastructure in China operates.

\section{Underinclusive IP Address Blocking}

For a subset of the sites we tested, we also attempted to reach the site at its IP address. To prevent access to a site completely, a filtering regime cannot block only its URL, but must also filter its IP address. We tested both the URL and the IP address during in-state testing for 29 sites; in 24 cases, the result was consistent (both were either blocked or accessible). Four sites (www.fofg.org, www.freetibet.org, www.tibet.com, and www.lnx-bbc.org) could not be reached at their URLs, but were accessible at their IP addresses. We believe that the blocking of www.lnx-bbc.org is inadvertent, and thus it is not surprising that its IP address is accessible. However, the other three sites clearly contain sensitive content, but are not filtered at their IP addresses. Thus, while China blocks both IP addresses and URLs to ensure that sensitive sites are filtered, it does not do so consistently.

\section{URL vs. Domain-Level Filtering}

Our research indicates that filtering states generally block on a domain-by-domain basis; they prevent access to an entire domain rather than filtering individual Web pages and URLs. The exceptions to this behavior tend to be domains containing large amounts of diverse, unrelated content, such as the free Web hosting domain geocities.com or Yahoo!'s groups. ${ }^{161}$ Our in-state testing in China, however, found several instances where particular URLs were blocked but the domain was accessible, though the source (authorship) of content appeared consistent across the domain. For example, the URL www.stanford.edu/group/falun was blocked, but www.stanford.edu was not. The following sites were blocked while their top-level URLs were accessible:

\footnotetext{
${ }^{161}$ In addition, commercial filtering software such as Secure Computing's SmartFilter often assigns different pages within a domain to different categories; thus, some pages, but not the entire domain, are filtered when a filtering state selects categories to block.
} 


\section{Figure 27 - Blocked Sites With Accessible Top-Level URLs}

\begin{tabular}{|l|}
\hline www.stanford.edu/group/falun/ \\
\hline public.planetmirror.com/pub/abit/download/drivers_update/voanews.com/ \\
\hline www.stumbleupon.com/url/www.voanews.com/ \\
\hline www.let.leidenuniv.nl/bth/falun.htm \\
\hline
\end{tabular}

This pattern may indicate filtering by URL string, blocking with no effort to investigate the nature of the content at a page, or an extremely aggressive attempt to locate and filter offensive content while preserving access to the bulk of the content of domains containing one or more site related to generally filtered content.

\section{F. E-mail Filtering}

E-mail is a vital Internet communications tool; ONI conducted a brief series of tests to evaluate whether, and how, China filters messages with sensitive content. Our results suggest that China does not filter e-mail messages at the backbone level of its network; instead, filtering is more likely to be performed by individual e-mail service providers, with little consistency among providers. ${ }^{162}$

Filtering technology for e-mail messages is well-developed due to the need to combat unsolicited bulk e-mail messages, commonly known as "spam." Spam filters are typically installed on e-mail servers; these filters search for specific patterns, keywords, or other characteristics of spam messages, such as altered message headers. If the filter detects a message that matches its definition of spam, it will typically reject the e-mail message, quarantine it, or tag it as spam. Many ISPs also block access to the IP addresses of mail servers associated with spammers.

To test China's e-mail filtering, ONI acquired five e-mail accounts (addresses) from free e-mail service providers in China. We created ten e-mail messages with sensitive content in the subject line and body text. ${ }^{163}$ We based the content of these messages on the monthly news summaries of significant events in China compiled by Human Rights In China (HRIC); these include information on arrests of political dissidents and religious persecution. We sent each of these ten messages in English to all five email accounts in China from two different e-mail accounts hosted outside China. We also sent each of the messages in Chinese twice (once encoded in the GB 2312 character set and once in Unicode) to the five email accounts in China.

In our tests, none of the politically sensitive e-mail messages we sent in English were blocked consistently. One of our e-mail accounts, with service provider 21cn.com, did not receive our first message containing information about the relatives of protesters injured at the Tiananmen Square protest, but 21cn.com did receive this message when we sent it from our second e-mail account. We observed the same pattern for the message about surveillance in China we sent to two accounts with providers 163.com and 21cn.com. Finally, messages sent in English about media censorship and religious

\footnotetext{
162 See Appendix 4 for complete results of our e-mail testing.

163 See Appendix 3 for brief descriptions of the contents of each of the ten e-mail messages.
} 
persecution were received at our sina.com.cn account from our first sending account, but not from our second account. Overall, when we analyzed results for the two sets of messages combined, every message with material on sensitive topics in English was received at all our e-mail accounts in China.

We tested the same messages in Chinese by sending two sets of these ten messages, encoded in different character sets. (There are multiple character encoding settings used to display Chinese characters. We sent messages encoded both in GB 2312, the official character set of the People's Republic of China, and in UTF-8 Unicode.) Our results varied depending on the encoding of the message.

In our Unicode testing, we found that all the messages were received, except for six of ten messages sent to our account at sina.com.cn. The six messages that we did not receive at our sina.com.cn account were those containing content on protests by Tiananmen mothers, media censorship, religious persecution, political dissidents, arrests and sentences, and petitions and protests. (However, we did receive each of these messages at sina.com.cn when they were encoded in GB 2312.)

In our GB 2312 testing, we saw much lower success rates at receiving messages. We did not receive three of the messages - those concerning the Tiananmen mothers, media censorship, and surveillance - at three or more of our five accounts. In addition, the message concerning religious persecution was not received at our citiz.net e-mail account.

Overall, our results do not suggest consistent e-mail filtering in China. None of our test messages containing sensitive content was blocked by all five e-mail service providers in China, indicating that filtering of e-mail traffic at the backbone level of the network either does not exist or is inconsistent. Instead, our results suggest that individual e-mail service providers may filter messages at the mail server level in a non-uniform fashion.

\section{G. Blog Filtering Testing}

Today, Chinese servers host an estimated 600,000 bloggers, who post content ranging from daily diaries to political commentary. ${ }^{164}$ Over the last year, China intensified efforts to control blogs' content. In March 2004, the state closed three popular, domestic blog providers, ${ }^{165}$ reportedly because a blogger posted a controversial letter regarding the Tiananmen Square incident and the SARS outbreak. ${ }^{166}$ Subsequently, all three providers were allowed to re-open, but implemented filtering mechanisms to control content posted to their blogs. These systems search for sensitive keywords when users attempt to post material.

In August 2004, Chinese hackers discovered a list of 987 sensitive keywords (in both Chinese and English) in a component of the popular QQ instant messaging. ${ }^{167}$ The software filters messages with these

\footnotetext{
${ }^{164}$ Estimates of the total number of blogs in China vary; we used the number provided by CNBlog.org, at http://www.cnblog.org/index.html.

${ }^{165}$ These providers are blogcn.com, blogbus.com, and blogdriver.com.

166 See Juliana Liu, China Shuts Down Two Internet "blog" Sites, Reuters, available at http://asia.news.yahoo.com/040318/3/1eig1.html (March 18, 2004); see also China Doctor Calls 1989 “Mistake,” BBC News, at http://news.bbc.co.uk/2/hi/asia-pacific/3542049.stm (March 8, 2004) (discussing the content of the letter criticizing China's response to the Tiananmen demonstrations).

167 See The Words You Never See in Chinese Cyberspace, China Digital News.
} 
keywords; the hackers posted the cracked list to a Chinese Bulletin Board System. ${ }^{68}$ The list includes terms in categories that includes national minorities' independence movements, the Tiananmen Square incident, Falun Gong, proper names of Chinese Communist Party leaders, and sensitive non-proper nouns (such as generic words relating to uprisings or oppression). ONI used this list of keywords to test the blog filtering mechanism for each of the three providers. We found that Blogbus and BlogCN filtered only 18 and 19 keywords, respectively, while Blogdriver filtered 350 of the terms. We discovered that, when triggered, the filtering software for BlogCN and Blogdriver prevented the user from completing the post and issued a pop-up alert. Blogbus replaced sensitive keywords with "*” characters. We also found that the controls were not fool-proof, and were able to bypass them by inserting characters, such as dashes, to split up sensitive keywords.

The censorship of Web logs demonstrates that China pursues a multi-pronged campaign to regulate the Internet, not only by limiting access to established Web sites, but also by controlling what content Chinese authors can post online domestically.

\section{H. Google Cache Testing}

Google is one of the most popular search engines for users worldwide. Google's cache function, though, allows users to access (at least intermittently) filtered content, because the request for that material goes to Google's servers, not to the blocked source's servers. ${ }^{169}$ Concerned by this circumvention method, China temporarily blocked access to Google in September $2002^{170}$; requests for Google's site were redirected to Chinese search engines. ${ }^{171}$ According to the company, Google negotiated with Chinese officials, and eventually access was restored. ${ }^{172}$

However, we found that while Google's site is accessible to Chinese users, ${ }^{173}$ the Google cache ${ }^{174}$ and certain keyword searches are blocked. To test access to Google in China, we connected to 37 Google servers from 11 remote computers located on four different backbone networks in China, and also from a remote testing facility. We found that the filtering mechanism blocking Google's cache is triggered by the text string "search?q=cache" in the HTTP GET request; this occurs whether the request is sent to a Google server or to a different site's server. A user making such a keyword request - seeking to access a site's cache - experiences disrupted access to the site. ${ }^{175}$

\footnotetext{
168 This list is archived at http://www.opennetinitiative.net/bulletins/008/bbs.pdf.

169 See, e.g., Gutmann, Losing the New China at 164-65.

${ }^{170}$ China Blocking Google, BBC News, at http://news.bbc.co.uk/2/hi/technology/2231101.stm (Sept. 2, 2002).

${ }^{171}$ Berkman Center for Intenet \& Society, Replacement of Google with Alternative Search Systems in China: Documentation and Screen Shots, at http://cyber.law.harvard.edu/filtering/china/google-replacements/ (Sept. 24, 2002).

172 See Jay Lyman, Google Responds to China Ban, NewsFactor Technology News, at http://www.newsfactor.com/perl/story/19279.html (Sept. 3, 2002); see also Tim Richardson, Google China Crisis Over, The Register, at http://www.theregister.co.uk/2002/09/12/google_china_crisis_over/ (Sept. 12, 2002).

173 See the enumeration report documenting our test results at http://www.opennetinitiative.net/bulletins/006/googleservers.html.

${ }^{174}$ See the enumeration report documenting our test results at http://www.opennetinitiative.net/bulletins/006/googlecacheservers.html.

175 See OpenNet Initiative, Probing Chinese Search Engine Filtering, at http://www.opennetinitiative.net/bulletins/005/index.html\#filtering (Aug. 19, 2004).
} 
However, the filtering system can be bypassed - inserting an ampersand (\&) into the HPPT GET request, such as "search?\&q=cache", allowed access to Google's cache. ${ }^{176}$ We could not access Web sites with sensitive keywords, such as "falun," in their URLs. The filtering mechanism appears specifically designed to target Google's cache, since caches of other popular search engines, such as Yahoo!, worked properly. 177

Although China no longer blocks Google entirely, a Chinese user will have a very different experience when using the search engine for some queries due to the state's filtering practices. Accessing Google's cache is a well-known method of ad-hoc circumvention of Internet censorship, and China's filtering mechanism seems designed specifically to close this loophole.

\section{Filtering by Chinese Search Engines Baidu and Yisou}

In July 2004, Reporters Sans Frontières admonished Google and Yahoo! as complicit in China's filtering practices based on the companies' holdings in two domestic Chinese search engines, Baidu.com and Yisou.com. ${ }^{178}$ We researched RSF's claims and confirmed that Baidu and Yisou filter by keyword and remove certain search results from their lists, but found that some keyword searches were blocked by China's gateway filtering and not the search engines themselves.

We searched Baidu and Yisou for various sensitive keywords, such as "free Tibet" and "falun." By refining our searches to look specifically within URLs as well as for page content, we concluded that the search engines index sensitive sites, but do not list them among search results. We posit that the search engine "crawlers" that compile results may be able to index content despite China's filtering - perhaps by operating from a remote location outside China - since the crawlers did index some sensitive sites. We also found that some cached versions of sensitive sites were sporadically available, leading us to conclude that filtering occurs "upstream," at the Internet infrastructure level.

Interestingly, our Baidu and Yisou testing provided important insight into the mechanics of China's Web filtering. When a user requests a banned keyword, the filtering system terminates that user's connection to the destination server by sending a TCP RST (reset) packet to the user, followed by advertising a TCP ZeroWindow size. ${ }^{179}$ This technique uses TCP's flow control feature to prevent the user's computer from transmitting additional data to the destination server (such as the Baidu.com search engine). This disconnection persisted for prolonged periods despite multiple attempts to reconnect.

We confirmed partially Reporters Sans Frontières' claims that the search engines Baidu and Yisou, with which Google and Yahoo! have investment relationships, filter the Web content they return when users search for certain sensitive keywords. However, this is only part of a set of complex,

\footnotetext{
${ }^{176}$ See the enumeration report documenting our test results at http://www.opennetinitiative.net/bulletins/006/googlecacheservers-mod.html.

177 See the enumeration report documenting our test results at http://www.opennetinitiative.net/bulletins/006/othersearchengines.html.

${ }^{178}$ Reporters Sans Frontières, Google - Yahoo Market Battle Threatens Freedom of Expression, at http://www.rsf.org/article.php3?id_article=11031 (July 26, 2004).

179 See OpenNet Initiative, Probing Chinese Search Engine Filtering, at

http://www.opennetinitiative.net/bulletins/005/\#res (Aug. 19, 2004); see generally Von Welch, A User's Guide to TCP Windows, at http://www.ncsa.uiuc.edu/People/vwelch/net_perf/tcp_windows.html (last updated June 19, 1996).
} 
overlapping filtering practices that include filtering in China's broader Internet infrastructure. Thus, we caution that any claims about filtering must incorporate analysis of the serious technical complexities of China's filtering regime.

\section{J. Restrictions on University On-Line Bulletin Board Systems}

China recently moved to impose stricter controls on the discussions taking place on university bulletin board systems (BBS). These message boards, some of which claimed hundreds of thousands of users, ${ }^{180}$ were immensely popular with students and with non-students users. As one of the few outlets for open, anonymous speech in China, the boards functioned as "virtual communities," serving as alternatives to state-run media ${ }^{181}$ or as dissemination points for critiques of the Communist Party. ${ }^{182}$ The boards also hosted tools to circumvent China's Internet censorship as well as discussions on sensitive topics like Tibet and Taiwan. ${ }^{183}$

As part of a Chinese Communist Party campaign to exercise tighter control over culture, education, and media, China's Education Ministry ordered the universities to censor the BBS. ${ }^{184}$ Its order stated that "[h]armful information should be detected and deleted... [message boards] on which harmful information has been spread should be shut down." 185 In justifying the government's reasoning, one official explained that " $\mathrm{t}] \mathrm{h}$ he message boards are too diverse, and students who read them are prone to rumor mongering.... Students don't watch TV or listen to radio but go to BBS and believe what they read. Many students with a right view do not speak on the BBS."186

The new restrictions limit BBS use to current students, cutting off access to all other users, including former students living abroad. ${ }^{187}$ This is a significant limitation on the BBS' reach -- one current student estimated that as many as half of the users on his university's message board system were non-students. ${ }^{188}$ The new regulations also require registration tied to the user's identity, eliminating the cherished anonymity the boards used to provide. ${ }^{189}$ These actions will undoubtedly curtail discussion and speech on the BBS. As one frustrated student lamented, "When we use our real names we are lying; when we use false names, we speak the truth." 190 The BBS crackdown provides a microcosm of China's Internet content filtering: when the state detects exchange of information on sensitive topics, it employs both legal and technical methods to curtail, and ultimately silence, this speech.

\footnotetext{
${ }^{180}$ Robert Marquand, Beijing Enforces the Party Line, Christian Science Monitor, Apr. 6, 2005, available at http://www.csmonitor.com/2005/0406/p01s04-woap.html

${ }^{181}$ Marquand, Beijing Enforces the Party Line.

182 Philip P. Pan, Chinese Crack Down on Student Web Sites, Washington Post, Mar. 23, 2005, at A13

${ }^{183}$ Benjamen Walker, Theory of Everything: Freedom on the March (radio broadcast, Apr. 3, 2005), available at http://www.toeradio.org/archives/2005/04/broadcast_18_fr.html.

${ }^{184}$ Marquand, Beijing Enforces the Party Line; Pan, Chinese Crack Down on Student Web Sites.

185 Marquand, Beijing Enforces the Party Line.

${ }^{186}$ Marquand, Beijing Enforces the Party Line.

187 Marquand, Beijing Enforces the Party Line.

${ }^{188}$ Walker, Theory of Everything: Freedom on the March.

${ }^{189}$ Pan, Chinese Crack Down on Student Web Sites.

190 Marquand, Beijing Enforces the Party Line.
} 


\section{$\underline{\text { K. Restrictions on On-Line Discussion Forums }}$}

On-line chats are extremely popular in China; a spokesperson for the site sina.com.cn told Reporters Sans Frontières that 4 million users employ its forums each day. ${ }^{191}$ A study by Reporters Sans Frontières (RSF) of censorship in these on-line discussion forums found that postings were filtered heavily, but inconsistently, and that users who persist in adding content on sensitive topics face exclusion from these services and, in extreme cases, even imprisonment. ${ }^{192}$

The RSF study found evidence of a complicated, and sometimes inconsistent, filtering regime for online discussion forums. The study states that most sites temporarily block all postings containing certain forbidden terms, but that forum Webmasters can override the automatic filter if, on review, the views expressed are deemed acceptable. (Such reviews are evidently uncommon since Webmasters spend most of their time monitoring forums for forbidden content, not attempting to restore improperly blocked posts.) Webmasters also manually remove messages with prohibited content that elude the automatic filters. These Webmasters are generally unpaid volunteers who are supervised by forum administrators charged with ensuring that no unacceptable material appears online.

In RSF's study, only 30\% of messages containing “controversial content" were posted successfully. While $55 \%$ of messages with controversial content made it into the forums initially, RSF found that more than half of these postings were removed by Webmasters. The most controversial posts, containing "direct criticism or demands targeted at the central government," either never appeared or were available only briefly. More moderate messages, with content on sensitive political topics but without criticism of the state, were successfully posted over $70 \%$ of the time, though some were later taken down. Almost $80 \%$ of messages containing only factual information on current topics made it into forums, except for xinhaunet.com, which filtered over half these posts.

As xinhaunet.com's blocking demonstrates, the level of filtering varied by forum. RSF found that, generally, "The most open Internet sites are the ones that are commercial enterprises. Competition within this sector encourages those in charge to test the limits of censorship." Thus, forums at 163.net and sina.com have more lenient filtering. In contrast, quasi-official sites, such as xinhuanet.com, censored postings critical of the government more stringently; RSF concluded that these "webmasters give priority to censoring messages that criticise the government." Criticism of China's handling of the SARS crisis was particularly targeted for censorship.

Users who post unacceptable material face exclusion from forums. The RSF researcher was eventually blocked from using her user ID at sina.com.cn; a Sina.com company spokesperson confirmed that such "blacklisting" occurs. In extreme cases, penalties can be severe: RSF described four cases of online dissidents who were arrested for posting "harmful messages."

\footnotetext{
${ }^{191}$ Reporters Sans Frontières, "Living dangerously on the Net": Censorship and surveillance of Internet forums, May 12, 2003, at http://www.rsf.org/article.php3?id_article=6793.

192 Reporters Sans Frontières, "Living dangerously on the Net": Censorship and surveillance of Internet forums.
} 


\section{CONCLUSION}

China makes a systematic, comprehensive, and frequently successful effort to limit the ability of its citizens to access and to post on-line content the state considers sensitive. At the level of legal regulation, China has a complex, overlapping system of laws, regulations, and informal methods that attempts to prevent the creation and distribution of banned material. At the technological level, the state employs a sophisticated infrastructure that filters content at multiple levels and that tolerates overblocking as the price of preventing access to prohibited sites. Importantly, China's filtering efforts lack transparency: the state does not generally admit to censoring Internet content, and concomitantly there is no list of banned sites and no ability for citizens to request reconsideration of blocking, as some other states that filter provide. The topics defined as sensitive, or prohibited, by China's legal code are broad and non-specific, and enforcement of laws such as the ban on spreading state secrets discourages citizens from testing the boundaries of these areas. China's legal and technological systems combine to form a broad, potent, and effective means of controlling the information that Chinese users can see and share on the Internet.

Moreover, the research we have conducted over several years - both individually as institutions and collectively as the ONI - demonstrates increasing sophistication of China's filtering regime. Its filtering system has become at once more refined and comprehensive over time, building a matrix of controls that stifles access to information deemed illegitimate by authorities. Considering that China's growing Internet population represents nearly half of all Internet users worldwide, and will soon overtake the United States as the single largest national group of Internet users, such extensive censorship should be of concern to all Internet users worldwide. China's advanced filtering regime presents a model for other countries with similar interests in censorship to follow. It has also shown a willingness to defend and even promote the principles of its filtering regime to international venues governing global communications, such as the World Summit of the Information Society. While there can be legitimate debates about whether democratization and liberalization are taking place in China's economy and government, there is no doubt that neither is taking place in China's Internet environment today. 


\section{$\underline{\text { APPENDIX } 1}$ \\ China Background}

\section{A. General Description}

The People's Republic of China (PRC) is located in eastern Asia, between North Korea and Vietnam. With a geographic area of approximately 3.7 million square miles and a population of 1.3 billion, China is one of the largest and most populous areas on Earth. ${ }^{193}$ Officially atheist since 2002, China's population includes adherents to Daoism, Buddhism, Islam, and Christianity. Describing itself as a "central democracy," China exists as a socialist state ruled by the Chinese Communist Party. ${ }^{194}$

Though it has the second-largest economy in the world, China still ranks low in per capita economic measures. China has attempted to integrate market-oriented systems with a political framework of strict and centralized Communist control. ${ }^{195}$ China is ranked 94 out of 177 states in 2004 on the United Nations Development Program's Human Development Index.196

\section{B. Political System}

The Chinese Communist Party controls the legislature, known as the National People's Congress (NPC), which is composed of 2,989 delegates serving five-year terms. The NPC appoints an executive State Council. ${ }^{197}$ While other political parties exist, none is recognized by China because they are considered subversive. ${ }^{198}$ The state is divided into 22 provinces, four municipalities directly under central government control, and five autonomous regions governed by local people's congresses. ${ }^{199}$

The Chinese Communist Party represses dissent, although traditional systems of social control and surveillance, such as the previously utilized "work unit", are being discarded in favor of structural reforms, greater social mobility, and strong economic growth. ${ }^{200}$ Nonetheless, independent organizations capable of mobilizing popular support are perceived as threats; for example, the Chinese state has vigorously suppressed the practice of Falun Gong ${ }^{201}$ and the separatist views of those who support freedom for Tibet.202

\footnotetext{
${ }^{193}$ China, Encyclopædia Britannica Online, at http://search.eb.com/eb/article?tocld=9117321. 194 CIA, The World Factbook -- China, Feb. 10, 2005, at http://www.cia.gov/cia/publications/factbook/geos/ch.html.

195 See generally U.S. Department of State, Background Note: China, at http://www.state.gov/r/pa/ei/bgn/18902.htm (Oct. 2004); Lucian W. Pye, The Spirit of Chinese Politics 1-11 (1992 ed.).

${ }^{196}$ United Nations Development Programme, Human Development Report 2004 at 139-140, July 15, 2004, at http://hdr.undp.org/reports/global/2004/.

${ }^{197}$ CIA, The World Factbook - China.

${ }^{198}$ CIA, The World Factbook - China.

${ }^{199}$ CIA, The World Factbook - China.

${ }^{200}$ With work units, state-owned factories provided salary, housing, education, and political indoctrination. See Economist Intelligence Unit, Country Briefings: China - Political Forces, at http://www.economist.com/countries/China/profile.cfm?folder=Profile\%2DPolitical\%20Forces (Feb. 9, 2004).

201 See Falun Gong: China's Dilemma, CNN.com, at http://edition.cnn.com/SPECIALS/2002/falungong/.

202 See The Dalai Lama: Man of Peace Takes His Place on World Stage, CNN.com, at http://www.cnn.com/SPECIALS/1999/china.50/inside.china/profiles/dalai.lama/.
} 


\section{APPENDIX 2}

\section{Entities Involved in Internet Regulation in China}

- Central Propaganda Department

- Department of Commerce

- Department of Telecommunications

- General Administration of Press and Publications

- Ministry of Culture

- Ministry of Information Industry

- Ministry of Public Security

- Public Security Bureau

- State Administration of Radio, Film, and Television

- State Council

- State Council Information Agency

- State Secrets Bureau 


\section{APPENDIX 3}

\section{In-Country Testing Results - Domains With Some Accessible and Some Inaccessible URLs}

\begin{tabular}{|c|c|}
\hline URL & Status \\
\hline http://members.aol.com/Sftrail/christ/comment/bible/ezra/ & Accessible \\
\hline http://members.aol.com/Tibetan/Monitor3.html & Accessible \\
\hline http://members.aol.com/yikhmongol/smff.htm & Accessible \\
\hline http://members.aol.com/bblum6/mem.htm & Accessible \\
\hline http://members.aol.com/casmasalc/ & Accessible \\
\hline http://members.aol.com/imppsite/ & Accessible \\
\hline http://members.aol.com/kurdis6065/Psk.html & Accessible \\
\hline http://members.aol.com/TeacherNet/Industrial.html & Accessible \\
\hline http://members.aol.com/imppsite/cnpage.htm & Inaccessible \\
\hline http://members.aol.com/imppsite/dcl.htm & Inaccessible \\
\hline http://members.aol.com/imppsite/index.htm & Inaccessible \\
\hline http://members.aol.com/TeacherNet/Medieval.html & Inaccessible \\
\hline http://www.fofg.org/act/act_join.php & Accessible \\
\hline http://www.fofg.org/chinese/index.php & Accessible \\
\hline http://www.fofg.org/news/news_category.php?cat_id=11 & Accessible \\
\hline http://www.fofg.org/news/news_story.php?doc_id=679 & Accessible \\
\hline http://www.fofg.org/voices/voices_story.php?doc_id=308 & Accessible \\
\hline http://www.fofg.org/ & Accessible \\
\hline http://www.fofg.org/chinese/persecution/persecution_bknd.php?cat_id=18 & Accessible \\
\hline http://www.fofg.org/news/news_category.php?cat_id=28 & Inaccessible \\
\hline http://www.fofg.org/news/news_story.php?doc_id=44 & Inaccessible \\
\hline http://www.fofg.org/news/news_story.php?doc_id=875 & Inaccessible \\
\hline http://edition.cnn.com/2001/WORLD/asiapcf/east/o6/o1/amnesty.tiananmen/ & Accessible \\
\hline http://edition.cnn.com/2002/WORLD/asiapcf/east/10/29/profile.jiang.zemin/ & Accessible \\
\hline http://edition.cnn.com/2003/WORLD/asiapcf/east/11/o9/china.net/ & Accessible \\
\hline http://edition.cnn.com/2005/WORLD/asiapcf/o1/16/china.zhao/ & Accessible \\
\hline http://edition.cnn.com/2001/WORLD/asiapcf/east/o2/26/taiwan.china.dissident/ & Accessible \\
\hline http://edition.cnn.com/2002/WORLD/asiapcf/east/o7/o8/china.gay/ & Accessible \\
\hline http://edition.cnn.com/2005/WORLD/asiapcf/o1/29/zhao.memorial/ & Inaccessible \\
\hline http://edition.cnn.com/SPECIALS/2002/falungong/ & Inaccessible \\
\hline http://edition.cnn.com/SPECIALS/2003/china.taiwan/ & Inaccessible \\
\hline http://edition.cnn.com/WORLD/asiapcf/9905/28/china.democracy/ & Inaccessible \\
\hline http://taiwansecurity.org/AFP/AFP-991224-China-Democracy-Party.htm & Accessible \\
\hline http://taiwansecurity.org/ST/2004/ST-150604.htm & Accessible \\
\hline http://taiwansecurity.org/LAT/LAT-990604.htm & Accessible \\
\hline http://taiwansecurity.org/ & Accessible \\
\hline http://taiwansecurity.org/News/FEER-0127200o-Village-Democracy.htm & Accessible \\
\hline
\end{tabular}




\begin{tabular}{|c|c|}
\hline http://taiwansecurity.org/News/FEER-990527.htm & Accessible \\
\hline http://taiwansecurity.org/Reu/Reu-990602.htm & Inaccessible \\
\hline http://taiwansecurity.org/TT/2005/TT-130105.htm & Inaccessible \\
\hline http://www.asiaweek.com/asiaweek/97/0502/nat7.html & Accessible \\
\hline http://www.asiaweek.com/asiaweek/features/power50.2001/po4.html & Accessible \\
\hline http://www.asiaweek.com/asiaweek/magazine/nations/o,8782,99515,oo.html & Accessible \\
\hline http://www.asiaweek.com/asiaweek/96/o216/nat6.html & Accessible \\
\hline http://www.asiaweek.com/asiaweek/daily/foc/o,8773,98300,oo.html & Accessible \\
\hline http://www.asiaweek.com/asiaweek/96/o614/nat4.html & Accessible \\
\hline http://www.asiaweek.com/asiaweek/magazine/nations/o,8782,165866,oo.html & Inaccessible \\
\hline http://www.cnn.com/2002/WORLD/asiapcf/east/07/23/china.falungong/ & Accessible \\
\hline http://www.cnn.com/ & Accessible \\
\hline http://www.cnn.com/2001/ASIANOW/east/o1/11/falun.gong.factbox/ & Inaccessible \\
\hline http://www.cnn.com/2003/ALLPOLITICS/12/o9/bush.china.ap/ & Inaccessible \\
\hline http://www.cnn.com/2003/WORLD/asiapcf/east/04/o3/china.rights.reut/ & Inaccessible \\
\hline http://www.cnn.com/2005/WORLD/asiapcf/o3/17/china.humanrights/ & Inaccessible \\
\hline $\begin{array}{l}\text { http://www.cnn.com/interactive/specials/9908/china.social.overview/content/religious.freedom. } \\
\text { html }\end{array}$ & Inaccessible \\
\hline http://www.cnn.com/SPECIALS/1999/china.50/5o.beyond/democracy.zhao/ & Inaccessible \\
\hline http://www.cnn.com/SPECIALS/1999/china.50/inside.china/profiles/dalai.lama/ & Inaccessible \\
\hline http://www.cnn.com/SPECIALS/1999/china.50/inside.china/profiles/jiang.zemin/ & Inaccessible \\
\hline http://www.cnn.com/SPECIALS/1999/china.50/red.giant/prisons/wu.essay/ & Inaccessible \\
\hline http://www.cnn.com/SPECIALS/china.summit/jiang.profile/ & Inaccessible \\
\hline http://www.cnn.com/WORLD/9706/04/tianamen.anniversary/ & Inaccessible \\
\hline http://www.cnn.com/WORLD/9706/o4/tiananmen.hong.kong/ & Inaccessible \\
\hline http://www.cnn.com/world/9711/16/china.unrest/ & Inaccessible \\
\hline http://www.cnn.com/WORLD/9711/16/wei/ & Inaccessible \\
\hline http://www.cnn.com/WORLD/asiapcf/9806/25/china.democracy/ & Inaccessible \\
\hline http://www.cnn.com/WORLD/asiapcf/9806/25/wei.interview/ & Inaccessible \\
\hline http://www.time.com/time/asia/asia/magazine/1999/990823/lama1.html & Accessible \\
\hline http://www.time.com/time/asia/features/falun_gong/ & Inaccessible \\
\hline http://www.time.com/time/asia/features/heroes/zhao.html & Inaccessible \\
\hline http://www.time.com/time/asia/features/xinjiang/cover.html & Inaccessible \\
\hline http://www.time.com/time/asia/features/youngchina/s.gay.author.html & Inaccessible \\
\hline http://www.time.com/time/asia/magazine/99/0927/democracy_wall.html & Inaccessible \\
\hline http://www.time.com/time/asia/magazine/article/o,13673,501031124-543843,00.html & Inaccessible \\
\hline http://www.time.com/time/asia/news/daily/o,9754,1018129,oo.html & Inaccessible \\
\hline http://www.time.com/time/asia/news/magazine/o,9754,165163,oo.html & Inaccessible \\
\hline http://www.time.com/time/poy/zemin.html & Inaccessible \\
\hline http://www.time.com/time/time10o/leaders/profile/rebel.html & Inaccessible \\
\hline http://www.yale.edu/ & Accessible \\
\hline http://www.yale.edu/falun/Pages/dymf/dymf_4.htm & Inaccessible \\
\hline
\end{tabular}


Internet Filtering in China in 2004-2005

\begin{tabular}{|l|l|}
\hline http://www.yale.edu/falun/zfl-html/zfl_3a.htm & Inaccessible \\
\hline http://www.yale.edu/yfp/archives/novembero4/novembero4_peace.htm & Inaccessible \\
\hline http://www.gluckman.com/DalaiLama.html & Accessible \\
\hline http://www.gluckman.com/FalunGong.html & Inaccessible \\
\hline http://www.gluckman.com/Tianan.html & Inaccessible \\
\hline
\end{tabular}


APPENDIX 4

\section{Results of E-mail Filtering Testing}

\begin{tabular}{|c|c|c|c|c|c|c|c|c|c|c|}
\hline \multicolumn{110}{|c|}{ Mnglish Messages - First Test } \\
\hline Provider & \multicolumn{10}{|c|}{ Message } \\
\hline & 1 & 2 & 3 & 4 & 5 & 6 & 7 & 8 & 9 & 10 \\
\hline http://mail.163.com/ & $\mathrm{Y}$ & $\mathrm{Y}$ & $\mathrm{Y}$ & $\mathrm{N}$ & $\mathrm{Y}$ & $\mathrm{Y}$ & $\mathrm{Y}$ & $\mathrm{Y}$ & $\mathrm{Y}$ & $\mathrm{Y}$ \\
\hline http://mail.21cn.com/ & $\mathrm{Y}$ & $\mathrm{n}$ & $\mathrm{Y}$ & $\mathrm{n}$ & $\mathrm{Y}$ & $\mathrm{Y}$ & $\mathrm{Y}$ & $\mathrm{Y}$ & $\mathrm{Y}$ & $\mathrm{Y}$ \\
\hline http://www.citiz.net/ & $\mathrm{Y}$ & $\mathrm{Y}$ & $\mathrm{Y}$ & $\mathrm{Y}$ & $\mathrm{Y}$ & $\mathrm{Y}$ & $\mathrm{Y}$ & $\mathrm{Y}$ & $\mathrm{Y}$ & $\mathrm{Y}$ \\
\hline http://mail.sina.com.cn/ & $\mathrm{Y}$ & $\mathrm{Y}$ & $\mathrm{Y}$ & $\mathrm{Y}$ & $\mathrm{Y}$ & $\mathrm{Y}$ & $\mathrm{Y}$ & $\mathrm{Y}$ & $\mathrm{Y}$ & $\mathrm{Y}$ \\
\hline http://mail.tom.com/ & $\mathrm{Y}$ & $\mathrm{Y}$ & $\mathrm{Y}$ & $\mathrm{Y}$ & $\mathrm{Y}$ & $\mathrm{Y}$ & $\mathrm{Y}$ & $\mathrm{Y}$ & $\mathrm{Y}$ & $\mathrm{Y}$ \\
\hline
\end{tabular}

\begin{tabular}{|c|c|c|c|c|c|c|c|c|c|c|}
\hline \multicolumn{10}{|c|}{ Chinese Messages - GB 2312 Encoding } \\
\hline \multicolumn{10}{|c|}{ Provider } & \multicolumn{10}{c|}{ Message } \\
\hline & 1 & 2 & 3 & 4 & 5 & 6 & 7 & 8 & 9 & 10 \\
\hline http://mail.163.com/ & $\mathrm{Y}$ & $\mathrm{N}$ & $\mathrm{Y}$ & $\mathrm{N}$ & $\mathrm{Y}$ & $\mathrm{Y}$ & $\mathrm{Y}$ & $\mathrm{Y}$ & $\mathrm{Y}$ & $\mathrm{Y}$ \\
\hline http://mail.21cn.com/ & $\mathrm{Y}$ & $\mathrm{n}$ & $\mathrm{n}$ & $\mathrm{n}$ & $\mathrm{Y}$ & $\mathrm{Y}$ & $\mathrm{Y}$ & $\mathrm{Y}$ & $\mathrm{Y}$ & $\mathrm{Y}$ \\
\hline http://www.citiz.net/ & $\mathrm{Y}$ & $\mathrm{Y}$ & $\mathrm{n}$ & $\mathrm{Y}$ & $\mathrm{n}$ & $\mathrm{Y}$ & $\mathrm{Y}$ & $\mathrm{Y}$ & $\mathrm{Y}$ & $\mathrm{Y}$ \\
\hline http://mail.sina.com.cn/ & $\mathrm{Y}$ & $\mathrm{Y}$ & $\mathrm{Y}$ & $\mathrm{Y}$ & $\mathrm{Y}$ & $\mathrm{Y}$ & $\mathrm{Y}$ & $\mathrm{Y}$ & $\mathrm{Y}$ & $\mathrm{Y}$ \\
\hline http://mail.tom.com/ & $\mathrm{Y}$ & $\mathrm{N}$ & $\mathrm{N}$ & $\mathrm{N}$ & $\mathrm{n}$ & $\mathrm{N}$ & $\mathrm{Y}$ & $\mathrm{Y}$ & $\mathrm{Y}$ & $\mathrm{Y}$ \\
\hline
\end{tabular}

\begin{tabular}{|cc|c|c|c|c|c|c|c|c|c|}
\hline \multicolumn{10}{|c|}{ English Messages - Second Test } \\
\hline \multicolumn{10}{|c|}{ Provider } & \multicolumn{10}{|c|}{ Message } \\
\hline & 1 & 2 & 3 & 4 & 5 & 6 & 7 & 8 & 9 & 10 \\
\hline http://mail.163.com/ & $\mathrm{Y}$ & $\mathrm{Y}$ & $\mathrm{Y}$ & $\mathrm{Y}$ & $\mathrm{Y}$ & $\mathrm{Y}$ & $\mathrm{Y}$ & $\mathrm{Y}$ & $\mathrm{Y}$ & $\mathrm{Y}$ \\
\hline http://mail.21cn.com/ & $\mathrm{Y}$ & $\mathrm{Y}$ & $\mathrm{Y}$ & $\mathrm{Y}$ & $\mathrm{Y}$ & $\mathrm{Y}$ & $\mathrm{Y}$ & $\mathrm{Y}$ & $\mathrm{Y}$ & $\mathrm{Y}$ \\
\hline http://www.citiz.net/ & $\mathrm{Y}$ & $\mathrm{Y}$ & $\mathrm{Y}$ & $\mathrm{Y}$ & $\mathrm{Y}$ & $\mathrm{Y}$ & $\mathrm{Y}$ & $\mathrm{Y}$ & $\mathrm{Y}$ & $\mathrm{Y}$ \\
\hline http://mail.sina.com.cn/ & $\mathrm{Y}$ & $\mathrm{Y}$ & $\mathrm{n}$ & $\mathrm{Y}$ & $\mathrm{n}$ & $\mathrm{Y}$ & $\mathrm{Y}$ & $\mathrm{Y}$ & $\mathrm{Y}$ & $\mathrm{Y}$ \\
\hline http://mail.tom.com/ & $\mathrm{Y}$ & $\mathrm{Y}$ & $\mathrm{Y}$ & $\mathrm{Y}$ & $\mathrm{Y}$ & $\mathrm{Y}$ & $\mathrm{Y}$ & $\mathrm{Y}$ & $\mathrm{Y}$ & $\mathrm{Y}$ \\
\hline
\end{tabular}

\begin{tabular}{|c|c|c|c|c|c|c|c|c|c|c|}
\hline \multicolumn{10}{|c|}{ Chinese Messages - Unicode (UTF-8) Encoding } \\
\hline Provider & \multicolumn{10}{|c|}{ Message } \\
\hline & 1 & 2 & 3 & 4 & 5 & 6 & 7 & 8 & 9 & 10 \\
\hline http://mail.163.com/ & $\mathrm{Y}$ & $\mathrm{Y}$ & $\mathrm{Y}$ & $\mathrm{Y}$ & $\mathrm{Y}$ & $\mathrm{Y}$ & $\mathrm{Y}$ & $\mathrm{Y}$ & $\mathrm{Y}$ & $\mathrm{Y}$ \\
\hline http://mail.21cn.com/ & $\mathrm{Y}$ & $\mathrm{Y}$ & $\mathrm{Y}$ & $\mathrm{Y}$ & $\mathrm{Y}$ & $\mathrm{Y}$ & $\mathrm{Y}$ & $\mathrm{Y}$ & $\mathrm{Y}$ & $\mathrm{Y}$ \\
\hline http://www.citiz.net/ & $\mathrm{Y}$ & $\mathrm{Y}$ & $\mathrm{Y}$ & $\mathrm{Y}$ & $\mathrm{Y}$ & $\mathrm{Y}$ & $\mathrm{Y}$ & $\mathrm{Y}$ & $\mathrm{Y}$ & $\mathrm{Y}$ \\
\hline http://mail.sina.com.cn/ & $\mathrm{Y}$ & $\mathrm{n}$ & $\mathrm{n}$ & $\mathrm{Y}$ & $\mathrm{n}$ & $\mathrm{Y}$ & $\mathrm{N}$ & $\mathrm{N}$ & $\mathrm{n}$ & $\mathrm{Y}$ \\
\hline http://mail.tom.com/ & $\mathrm{Y}$ & $\mathrm{Y}$ & $\mathrm{Y}$ & $\mathrm{Y}$ & $\mathrm{Y}$ & $\mathrm{Y}$ & $\mathrm{Y}$ & $\mathrm{Y}$ & $\mathrm{Y}$ & $\mathrm{Y}$ \\
\hline
\end{tabular}




\section{Legend}

$\mathrm{Y}=\mathrm{E}$-mail Message Received

$\mathrm{N}=$ Email Message Not Received, Error Message Delivered to Sender

n = E-mail Message Not Received, No Error Message Delivered to Sender

\begin{tabular}{|l|l|}
\hline $\begin{array}{l}\text { Message } \\
\text { Number }\end{array}$ & Contents \\
\hline 1 & Death Penalty Data on China \\
\hline 2 & Tiananmen Mothers' Criticism of Government's Actions \\
\hline 3 & Media Censorship by China \\
\hline 4 & Police Surveillance of Dissidents \\
\hline 5 & Religious Persecution of Falun Gong \\
\hline 6 & Deaths of Coal Miners in Underground Explosion \\
\hline 7 & Detention of Political Dissidents \\
\hline 8 & Arrest and Sentencing of Tibetan Monks \\
\hline 9 & Petitions and Protests by Political Activists on Human Rights \\
\hline 10 & Arrest of Writer for Advocating Uighur Independence \\
\hline
\end{tabular}

